\title{
Aerogeophysical characterization of an active subglacial lake system in the David Glacier catchment, Antarctica
}

\author{
Laura E. Lindzey ${ }^{1,2, a}$, Lucas H. Beem ${ }^{3}$, Duncan A. Young ${ }^{1}$, Enrica Quartini ${ }^{1,2, b}$, Donald D. Blankenship ${ }^{1,3}$, \\ Choon-Ki Lee ${ }^{4}$, Won Sang Lee ${ }^{4}$, Jong Ik Lee ${ }^{5}$, and Joohan Lee \\ ${ }^{1}$ University of Texas Institute for Geophysics, University of Texas at Austin, Austin, TX, USA \\ ${ }^{2}$ Department of Geological Sciences, Jackson School of Geosciences, University of Texas at Austin, Austin, TX, USA \\ ${ }^{3}$ Montana State University, Bozeman, Montana, USA \\ ${ }^{4}$ Unit of Ice Sheet and Sea Level Changes, Korea Polar Research Institute, Incheon 21990, South Korea \\ ${ }^{5}$ Division of Polar Earth-System Sciences, Korea Polar Research Institute, Incheon 21990, South Korea \\ ${ }^{6}$ Division of Polar Technology, Korea Polar Research Institute, Incheon 21990, South Korea \\ a now at: Department of Ocean Engineering, University of Washington Applied Physics Laboratory, Seattle, WA, USA \\ b now at: Georgia Institute of Technology, Atlanta, Georgia, USA
}

Correspondence: L. E. Lindzey (lindzey@uw.edu)

Received: 12 September 2019 - Discussion started: 15 October 2019

Revised: 12 May 2020 - Accepted: 19 May 2020 - Published: 15 July 2020

\begin{abstract}
In the 2016-2017 austral summer, the University of Texas Institute for Geophysics (UTIG) and the Korea Polar Research Institute (KOPRI) collaborated to perform a helicopter-based radar and laser altimeter survey of lower David Glacier with the goals of characterizing the subglacial water distribution that supports a system of active subglacial lakes and informing the site selection for a potential subglacial access drilling project. This survey overlaps with and expands upon an earlier survey of the Drygalski Ice Tongue and the David Glacier grounding zone from 2011 and 2012 to create a $5 \mathrm{~km}$ resolution survey extending $200 \mathrm{~km}$ upstream from the grounding zone. The surveyed region covers two active subglacial lakes and includes reflights of ICESat ground tracks that extend the surface elevation record in the region. This is one of the most extensive aerogeophysical surveys of an active lake system and provides higher-resolution boundary conditions and basal characterizations that will enable process studies of these features. This paper introduces a new helicopter-mounted ice-penetrating radar and laser altimetry system, notes a discrepancy between the original surfaceelevation-derived lake outlines and locations of possible water collection based on basal geometry and hydraulic potential, and presents radar-based observations of basal conditions that are inconsistent with large collections of ponded
\end{abstract}

water despite laser altimetry showing that the hypothesized active lakes are at a highstand.

\section{Introduction}

David Glacier is a large East Antarctic outlet glacier, draining $\sim 4 \%$ of the East Antarctic Ice Sheet (Rignot, 2002) through the Transantarctic Mountains and into the western Ross Sea. Smith et al. (2009) identified six active lakes in the David Glacier catchment, and their location near the Korea Polar Research Institute's (KOPRI) Jang Bogo Station makes them an attractive target for a detailed geophysical study. Hypothesized outlines for the lakes are shown in Fig. 1, and they are numbered ascending with distance from the grounding zone, with D1 the farthest downstream. Over the ICESat period (2003-2009), lakes D1, D4, D5, and D6 were observed to be filling, while both D2 and D3 were observed to be draining. A more recent analysis using CryoSat-2 data compared the patterns of surface elevation change within and outside the D1 and D2 lake polygons and concluded that these might not be true lake features because the surface elevation changes were small and did not have a phase difference across the nominal lake boundaries (Siegfried and Fricker, 2018). 

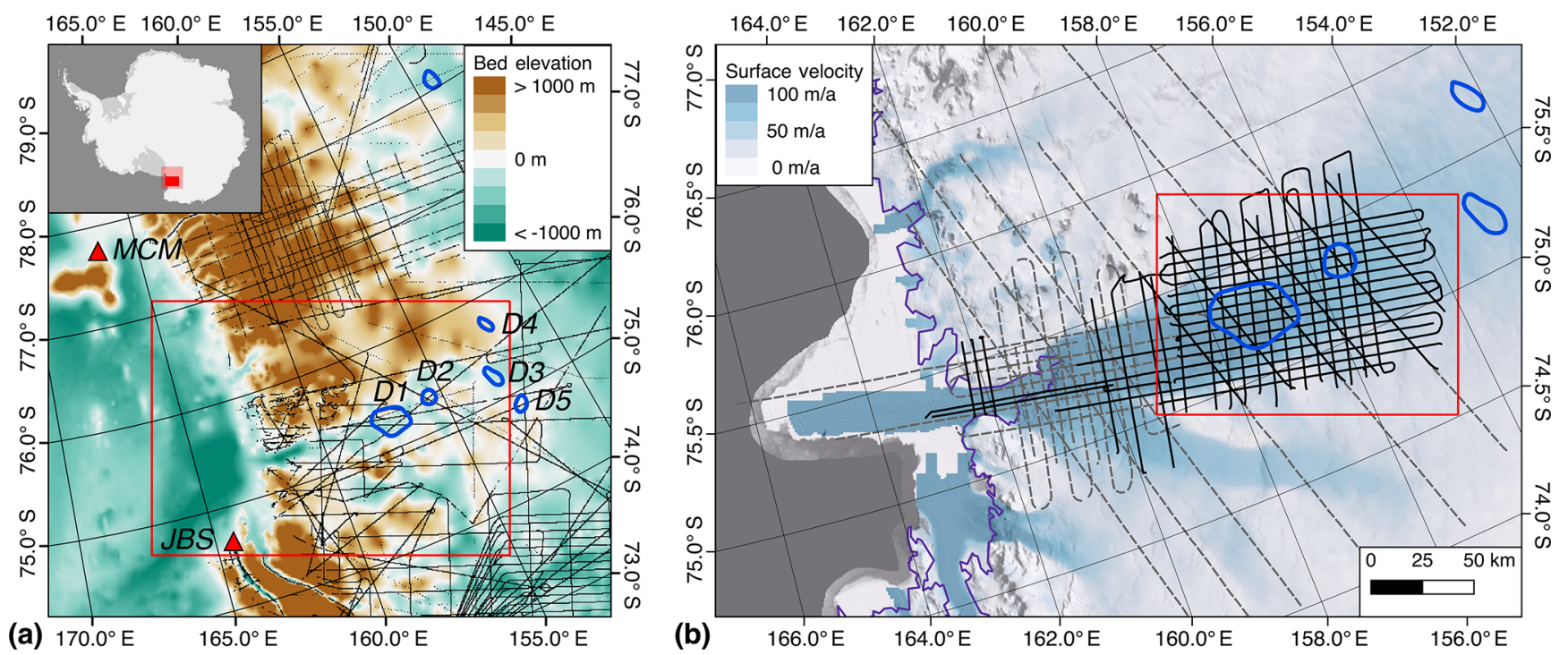

Figure 1. (a) Context of David Glacier, showing Bedmap2 bed elevations and radar echo sounding (RES) coverage (Fretwell et al., 2013) prior to the survey reported here. The Antarctic Surface Accumulation and Ice Discharge (ASAID) grounding line is shown in purple (Bindschadler et al., 2011), and active lakes are outlined in blue and labeled according to Smith et al. (2009). The locations of Jang Bogo (JBS) and McMurdo (MCM) stations are shown with red triangles, and the red box indicates the extent of panel (b). The inset shows locations of panels (a) and (b). (b) Locations of post-Bedmap2 RES data. Dashed gray lines were flown by the International Collaborative Exploration of the Cryosphere by Airborne Profiling (ICECAP) in the 2010 and 2011 seasons (ICP3, ICP4). The black lines are flights from the 2016 KOPRI season. Only the 2016 data were used in this work. The background is surface velocity (Rignot et al., 2011a) over the MODIS mosaic (Scambos et al., 2007). The red box indicates the extent of Figs. 4, 6, and 8-11. This figure was created using QGIS (QGIS.org, 2016) and Quantarctica (Matsuoka et al., 2018).

After their first identification using RADARSAT interferometric synthetic aperture radar (InSAR) on the Siple Coast (Gray et al., 2005), individual active lakes were observed by orbital remote sensing at locations across Antarctica, including Adventure Subglacial Trench (Wingham et al., 2006), Whillans Ice Stream (Fricker et al., 2007), and Byrd Glacier (Stearns et al., 2008). This was followed by a continent-wide inventory based on the ICESat surface elevation time series (Smith et al., 2009). These surface features were initially hypothesized to reflect the motion of water at the bed based on their monopole nature and the isolated areas of elevation change that occur in consistent locations over time. In further support of a hydrological origin of these features, potential water routing and even volume balance have been established for the Adventure Subglacial Trench lakes (Wingham et al., 2006; Carter et al., 2009). In addition, the Whillans Ice Stream Subglacial Access Research Drilling (WISSARD) project found a thin cavity $(\sim 1 \mathrm{~m})$ of water (Tulaczyk et al., 2014) after drilling into subglacial Lake Whillans. Presumed active lake drainage events have also been associated with ice acceleration in the Byrd Glacier (Stearns et al., 2008), Whillans and Mercer ice streams (Siegfried et al., 2016), and Thwaites Glacier (Smith et al., 2017) catchments, which would be consistent with hydrologically induced modification of the basal boundary conditions.
In addition to occurring in a range of geological settings, active lake drainage events have been observed as a response to both climatic and internal forcings. As an example of the former (and an outlier among active lake observations), Scambos et al. (2011) identified a subglacial lake drainage event apparently triggered by the lowering of Crane Glacier subsequent to the collapse of the Larsen B Ice Shelf. Many of these features have been observed to be cyclical, indicating that they are not all one-time events triggered by crossing a physical threshold due to changing driving forces and instead are an ongoing feature of Antarctic hydrology occurring independently of changes to ice sheet geometry. In this view, active lakes are features of the subglacial hydrologic systems representing a stable limit cycle that naturally occurs whenever total melt produced by shear margin heating, basal friction, and/or geothermal flux lies in a critical range too high to be drained via distributed flow and too low to keep channels open. This mechanism appears in the model developed by Werder et al. (2013) and is applied to an idealized Antarctic system by Dow et al. (2016).

Other work has used the lake outlines from Smith et al. (2009) to constrain ice sheet models. First, it is reasonable to assume that the region of an active lake is at the pressure melting point, which in turn can be a constraint on geothermal heat flux (Van Liefferinge et al., 2018). Lake boundaries are also used to assume regions of zero basal shear stress 
(e.g Matsuoka et al., 2012; Pattyn, 2010). These usages are dependent on the assumption that active lake boundaries exactly correspond to the extent of the surface expression and represent ponded water independent of lake stage.

Better understanding the potential link between active lakes and ice dynamics requires a better characterization of subglacial water organization, ideally with an observation of basal conditions that is also associated with ice dynamics. A number of ice-penetrating radar surveys have traversed or flown over active lake sites, and significant differences exist between the radar signature observed at active lakes and established radar lakes (e.g., Siegert et al., 1996; Wright et al., 2012).

Subglacial lakes have long been identified as bright, specular locations in radargrams that are also hydraulically flat and at a local hydraulic potential minimum (Oswald and Robin, 1973; Siegert et al., 1996; Carter et al., 2007; Wright et al., 2012). Some of these locations have been shown to correspond to deep, stable lakes (Kapitsa et al., 1996). The criteria have varied slightly based on the author and data used, and radar-based requirements include relative or absolute brightness based on reflection coefficient analysis and smoothness as inferred from the lack of fading (Carter et al., 2007) or high specularity content (Young et al., 2017). Some subglacial lakes have been hypothesized based on their ice surface expression alone (Jamieson et al., 2016).

There have been a number of radar studies of active lake regions (Welch et al., 2009; Langley et al., 2011; Christianson et al., 2012; Wright et al., 2012; Siegert et al., 2014). Most attempt to apply the Carter et al. (2007) lake detection criteria to the basal horizon under the lake outline proposed by Smith et al. (2009), which usually fails to result in a "definite" lake. There have been a handful of exceptions to this, where newly discovered active lakes previously appeared in a radar lake inventory. Subglacial Lake Mercer appeared in the inventory of Carter et al. (2007) as a definite lake (Fricker and Scambos, 2009), though the rest of the Siple Coast active lakes did not. Additionally, the recipient lakes of the Adventure Subglacial Trench flood were in an existing inventory (Wingham et al., 2006; Siegert et al., 2005), and there are "fuzzy lakes" (lakes lacking a coherent reflection; Carter et al., 2007) along its flow path (Carter et al., 2009).

More commonly, these investigations have found a minimum in the basal hydraulic potential and a region of elevated reflection coefficient corresponding with the surface feature. For example, using a survey with multiple ice-penetrating radar transects intersecting over a single lake, Siegert et al. (2014) investigated radar characteristics of an active lake in the Institute Ice Stream and observed that the surface elevation signal was associated with an apparently bright (but not smooth or flat) region on the downstream side of a bedrock bump.

Elsewhere, indications of subglacial water have been entirely absent. In the Byrd catchment, Welch et al. (2009) looked at ground-penetrating radar data from a traverse, and
Wright et al. (2014) used airborne ice-penetrating radar to investigate a number of the active lakes identified in the Smith et al. (2009) catalog. None of the locations had clear radar echo sounding (RES) evidence of a water-ice basal interface, and Wright et al. (2014) point out that their survey covered a large enough number of lakes that all of them being drained would be unlikely. Langley et al. (2011) attempted similar analysis in the upper Recovery system. Welch et al. (2009) and Langley et al. (2011) conclude that their observations are consistent with a drained or nonexistent lake, but both fail to compare surface altimetry to the ICESat record to determine whether this is consistent with the surface-elevation-derived lake stage.

In this paper, two active subglacial lakes and the surrounding basal environment are surveyed by airborne radar. The survey results show no distinct bed character in either reflection coefficient or specularity content beneath the previously established polygons describing lake extent. Instead the regions show a high degree of heterogeneity, anisotropy, and surface elevation change inconsistent with their boundaries. These results further confound what the definition of active subglacial lakes should be and how they fit into the broader hydrological system.

\section{Data}

\subsection{Platform}

This paper describes data collected during the 2016-2017 field season using an AS-350 helicopter to fly a VHF radar designed by the University of Texas Institute for Geophysics (UTIG; Fig. 2). Additional science instrumentation included a Renishaw laser altimeter and a Canon dSLR camera. For precise positioning of the data a Trimble Net-R9 dualfrequency carrier-phase GNSS and a Novatel SPAN IGM-1A inertial navigation system were used. After initial test flights, the instruments did not require an operator on board; the pilot had a power switch that was used to disable VHF transmission when necessary. All flights were based out of South Korea's Jang Bogo Station and were supported by KOPRI.

\subsection{Laser altimeter}

A Renishaw ILM-1200-HR $905 \mathrm{~nm}$ laser altimeter was mounted to the right of the pilot's seat, collocated with the camera and utilizing an existing downward-facing window in the helicopter. It provided raw range measurements at $1000 \mathrm{~Hz}$ with $1 \mathrm{~cm}$ precision, and its effective maximum range in Antarctic conditions was $\sim 900 \mathrm{~m}$. The raw serial stream was recorded by the same acquisition system as the radar data, which provides synchronous timestamps with reference to GPS time. 


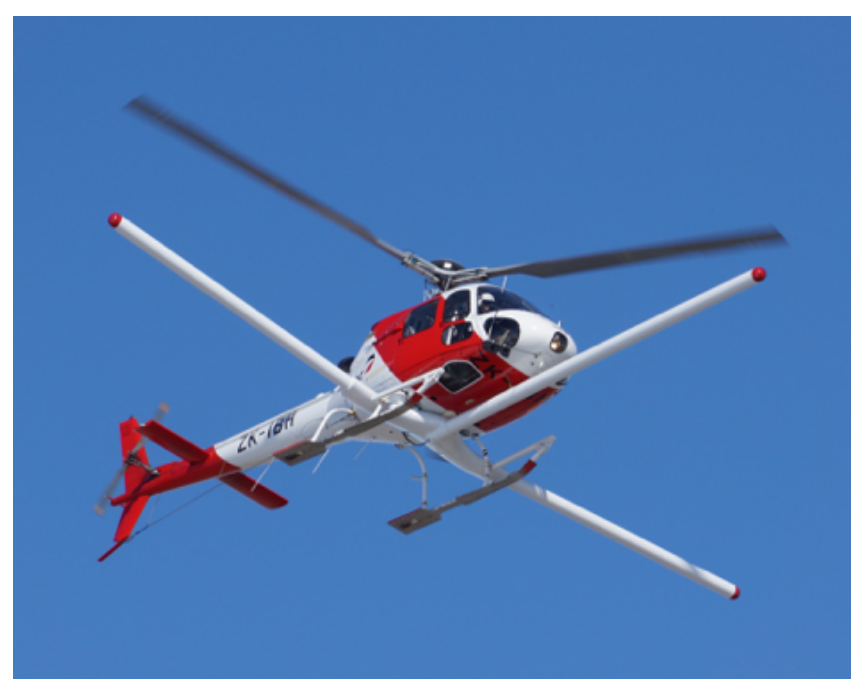

Figure 2. Helicopter in survey configuration. Radar antennas were mounted in the lateral booms, which measure $11.52 \mathrm{~m}$ from tip to tip; the front boom was empty. The laser altimeter and dSLR camera were mounted to the right of the pilot's seat using a pre-existing window.

\subsection{Ice-penetrating radar}

The new instrument described here is a direct descendant of a lineage of coherent radars that started with an experimental field season in 2001. The original system, termed the High-Capability Airborne Radar Sounder (HiCARS; Peters et al., 2005), was a hybrid of a JPL-designed coherent radar (Moussessian et al., 2000) and the Technical University of Denmark (TUD) $60 \mathrm{MHz}$ airborne ice-penetrating radar system (Skou and Søndergaard, 1976). It was first mounted on a Twin Otter airplane in 2001 to perform surveys of the Siple Coast (Peters et al., 2005), South Pole, and the B15a iceberg (Peters et al., 2007b). This was followed by the 2005 Airborne Geophysical Survey of the Amundsen Sea Embayment, Antarctica (AGASEA), survey of Thwaites, also using Twin Otters (Holt et al., 2006). Since 2008, the International Collaborative Exploration of the Cryosphere by Airborne Profiling (ICECAP) project has been fielding similar radars using a DC-3T airplane, and UTIG entirely redesigned the electronics with a focus on using commercial, off-the-shelf components to create the HiCARS2 radar in 2010 (Blankenship et al., 2017a, b). In 2014, independent recording from each antenna was added to create the Multifrequency Airborne Radar Sounder with Full-phase Assessment (MARFA; Castelletti et al., 2017), in which digitizer improvements also enabled the replacement of local-oscillator-based down conversion with bandpass sampling. The system described in this paper uses the same electronics as MARFA but with custom antennas for installation on an AS-350 helicopter.

The radar transmits $1 \mu$ s wide chirps, linearly sweeping the frequency from 52.7 to $67.5 \mathrm{MHz}$ with a $6250 \mathrm{~Hz}$ pulse rep- etition frequency and $8 \mathrm{~kW}$ peak pulse power. Using separate 14-bit digitizers with low gain for the surface and higher gain for the bed, the system independently records the received signal from each antenna at 50 Msamples s $^{-1}$, with a total trace length of 3200 samples. The record is stacked 32 times in hardware, then written to disk with 16-bit precision at $196 \mathrm{~Hz}$. This resulted in one raw trace every $18 \mathrm{~cm}$ alongtrack at an average helicopter ground speed of 70 knots, or $42 \mathrm{~cm}$ at the DC-3T ground speed of 160 knots.

The ability to compare data between HiCARS, HiCARS2, MARFA, and the present system has been considered to be of paramount importance in developing and fielding the new system. The required processing techniques are functionally identical, with differences confined to peak power output and gains as well as the platform-dependent antennas.

The airplane antennas have a heritage dating back to the TUD radar from the 1970s. They are center-fed flat-plate dipole antennas installed inside an airfoil and mounted 1/4 wavelength under the wings. The helicopter's antennas were designed to fit inside existing flight-certified booms originally designed for magnetometer surveys. These geometric constraints led to an end-fed design with an end plate installed in each lateral boom; the forward boom was empty. The lack of an airplane wing providing a ground plane means that the upward lobe is not reflected, yielding $6 \mathrm{~dB}$ lower total system gain. Additionally, the smaller separation between the antennas yields a wider central lobe, leading to increased surface scattering that can be mitigated by flying closer to the ice surface. There is no evidence in the data for timevarying interference due to the helicopter blades rotating at $\sim 400 \mathrm{rpm}$

\section{Methods}

\subsection{Positioning}

Processing of GPS observations was performed using Novatel's Waypoint GrafNav software, which reports $\sim 15 \mathrm{~cm} \sigma$ for precision. All data in this paper are reported with reference to the WGS84 ellipsoid.

\subsection{Laser altimeter}

All analyses presented in this paper used data that geolocated the median of 100 raw range measurements, which spans $\sim$ $3.6 \mathrm{~m}$ along-track.

\subsubsection{Calibration}

The laser's mounting bias relative to the inertial navigation system was solved in a two-step process, similar to Young et al. $(2008,2015)$. The first step used a digital level to obtain a coarse estimate of roll and pitch, but this is insufficient to obtain the desired accuracy in geolocation. In the second step, the measured values are used as the initial seed 


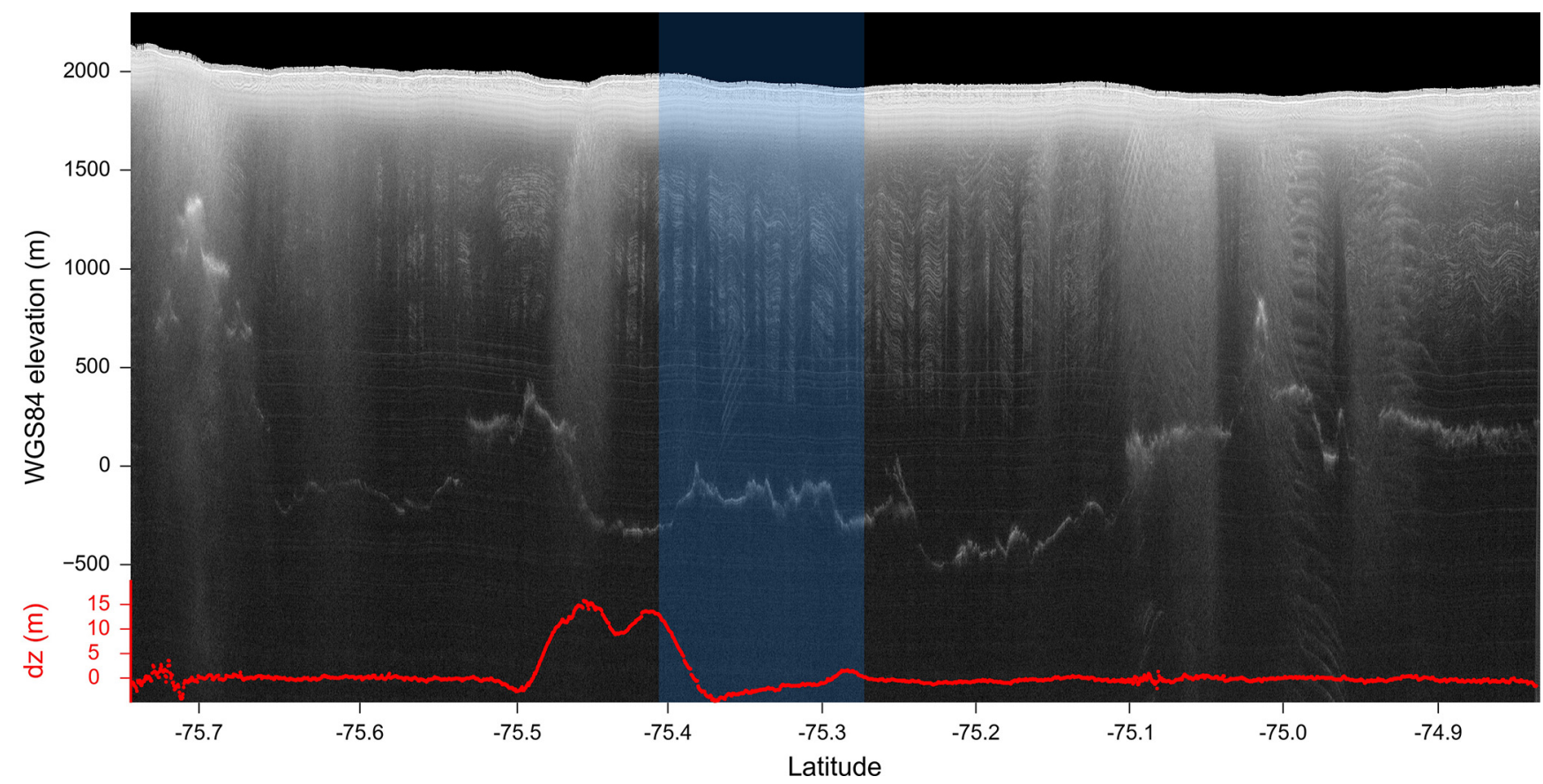

Figure 3. Focused radargram DVG/IBH0c/GL0328c. The location of the transect is shown in Fig. 7, and its overlap with the D2 lake outline is highlighted in blue. Observed surface elevation change since 2003 is shown in red. The radargram has been depth-corrected based on laser surface elevations and truncated $20 \mathrm{~m}$ above the surface.

for a minimization of crossover errors based on data from a dense grid with 150 crossovers flown at three different elevations over a smooth region of the Nansen Ice Shelf. The resulting calibration used crossover points to compare surface elevations and yielded a standard deviation of $44 \mathrm{~cm}$ within that grid. Validation was performed by comparing the new surface elevation estimates to raw ICESat surface elevations where available over slow-moving ice; this revealed no bias in the reported ranges.

\subsubsection{Surface elevation}

The subglacial lake state at the time of the 2017 survey is determined using two different methods of comparing the new laser altimetry data to the 2003-2009 ICESat surface elevation record. ICESat's Geoscience Laser Altimeter System (GLAS) measured ice surface elevations at $172 \mathrm{~m}$ alongtrack spacing with a $\sim 60 \mathrm{~m}$ radius footprint and $15 \mathrm{~cm}$ vertical accuracy (Zwally et al., 2002). It collected data on $91 \mathrm{~d}$ repeat orbits with ground tracks separated by $\sim 14-20 \mathrm{~km}$ in the David Glacier region. Comparison of surface elevation data along repeat tracks is complicated by the fact that the GLAS instrument did not precisely point at the reference track; elevation differences due to cross-track surface slope confound differences due to actual surface elevation change.

First, crossovers between the 2017 survey's along-flow lines and all available ICESat data are compared. This is the simplest method of processing surface elevation change since it compares data at overlapping points and therefore does not require any correction for surface slopes. The resulting elevation change observations are both sparser along the GLAS lines (as determined by the survey spacing) and denser between the nominal GLAS lines because it is possible to include all of the off-nominal tracks from early in the ICESat era. Across the entire survey, the mean elevation difference is $-0.04 \mathrm{~m}$, and the median is $-0.20 \mathrm{~m}$, which provides a rough validation of the calibration for the helicopter's laser altimeter.

Next, reflown ICESat tracks are used to compute surface elevation change. This requires adding a correction for crosstrack slope since neither the original ICESat orbits nor the reflights exactly sampled the ground track. This paper follows the method from Smith et al. (2009) to estimate surface slope: perform linear regression to solve for $\frac{\mathrm{d} z}{\mathrm{~d} x}, \frac{\mathrm{d} z}{\mathrm{~d} y}$, and $\frac{\mathrm{d} z}{\mathrm{~d} t}$ using all GLAS surface elevation measurements in overlapping windows measuring $700 \mathrm{~m}$ along-track at $500 \mathrm{~m}$ intervals. For each GLAS point, we calculated $d z$ as the vertical distance between that point and the plane that passes through the nearest new observation with the GLAS-based surface slopes. Any GLAS point farther than $500 \mathrm{~m}$ from the nearest point in the new survey is discarded.

\subsection{Ice-penetrating radar}

For this work, we used the 1D-focused processing for radargrams described in Peters et al. (2007a) for geometry and basal reflectivity, complemented with 2D focusing to derive specularity content (Schroeder et al., 2015). Figure 3 
shows an example radargram that crosses D2. Focusing is performed by convolving a kernel with pulse-compressed radar data, where the kernel is generated based on the expected appearance (delay and phase) of a point scatterer at that location, which is a function of airplane height, ice thickness, and surface slope. Different aperture lengths are used for focusing, which correspond to the 1D and 2D nomenclature in Peters et al. (2007a). One-dimensional focusing uses a short enough aperture that range changes are less than a pulse width; for a longer aperture, a 2D kernel (in this case accommodating $1 \mu \mathrm{s}$ of range change) is required to match the phase history, further improving resolution, collection of scattered energy, and detection of sloping interfaces at some cost to the signal-to-noise ratio.

\subsubsection{Topography}

For estimating the bed elevation and ice thickness, the radar reflection off the basal interface was identified by a manual process that labels the first-returned continuous reflector (Blankenship et al., 2001). The right-side radar antenna had a stall strip that raised its noise floor, so labeling was performed on the data from the left antenna only (further processing used the combined product). Due to the existence of side lobes in the transmit-receive beam pattern, the first return criteria may underestimate ice thickness in rough terrain, overestimate the width of mountains and ridges, and possibly fail to detect valley floors and lakes. Given the surface and bed horizons, ice thickness is calculated using $168.42{\mathrm{~m} \mu \mathrm{s}^{-1}}^{-1}$ as the speed of light in ice without a correction for the firn density gradient. The bed elevation product results from subtracting this ice thickness from the laser-determined surface elevation.

All intersecting lines where bed picks were recovered within a $100 \mathrm{~m}$ radius are used to characterize the uncertainty in bed elevation estimates. There is no attempt to reconcile differing bed estimates from intersecting transects in the labeling process: picking is purely based on the first-return criteria. This means that the computed crossover differences are valid for projecting to regions without crossovers but with equivalently rough topography. These crossover differences are shown in Fig. 4. Of the 450 locations where survey lines intersected and a bed was recovered, $76 \%$ had differences less than $50 \mathrm{~m}, 88 \%$ had differences less than $100 \mathrm{~m}$, and $95 \%$ were under $200 \mathrm{~m}$. There was no clear spatial pattern to the distribution of errors, and inspection of the six intersections with a difference greater than $400 \mathrm{~m}$ revealed that the apparent errors were consistent with the observed alongtrack variation in bed elevation at length scales equivalent to the across-track beam width.

Generation of the digital elevation model (DEM) started with the full-density bed elevation points from every trace at which a bed return was detected. These profiles are preprocessed for gridding by sampling to a $500 \mathrm{~m}$ cell size using the Generic Mapping Tools' (Wessel and Smith, 1998,

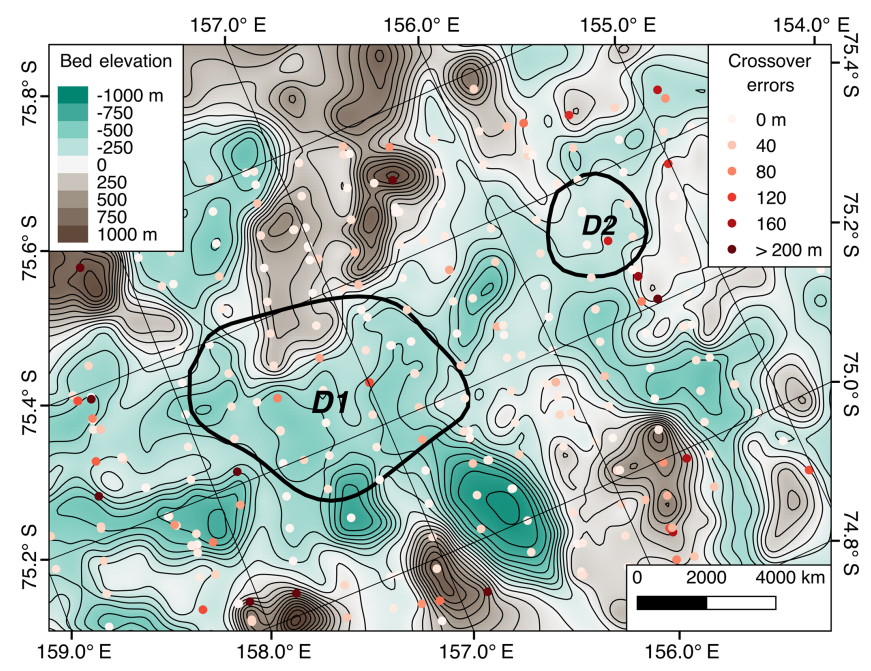

Figure 4. Bed elevation DEM generated from KOPRI data, with $100 \mathrm{~m}$ contours and errors in bed elevation between intersecting lines. Lake outlines from Smith et al. (2009) are black.

1991) blockmean function. Natural neighbor interpolation was performed on this decimated dataset using matplotlib's (Hunter, 2007) griddat a function, which is based on Delaunay triangulation. This interpolation retained artifacts along the flight lines, so a $1 \mathrm{~km}$ standard deviation Gaussian filter was applied as a final step. The DEM presented here reports the ice-water interface beneath floating ice; it makes no attempt to mask the grounding line or correct for the water column to determine bathymetry.

Profile-based ice thicknesses can be problematic to grid due to their anisotropic sampling density. This dataset's line spacing does not support using a higher-resolution DEM; therefore, when compared to the raw data, there are sometimes significant gridding errors. They are particularly noticeable in higher-relief areas, where bed features are flattened and broadened. Unlike the crossover errors, these gridding errors follow a roughly normal distribution, with a standard deviation of $95 \mathrm{~m}$. Of the approximately half million bed elevation measurements, $53 \%$ differ from the gridded product by less than $50 \mathrm{~m}$ error, $79 \%$ by less than $100 \mathrm{~m}$, and $95 \%$ by less than $200 \mathrm{~m}$.

\subsubsection{Hydraulic potential}

Overall subglacial water flow is largely controlled by hydraulic potential gradients. The organization of the subglacial hydrology is controlled by the geometrical boundary conditions in concert with water production, temperature gradients, and basal substrate. Remote sensing allows us to characterize the large-scale geometric contributions to hydraulic potential, which is typically expressed as follows (Paterson, 1994):

$\phi=z_{\text {bed }} \rho_{\text {water }}+h \rho_{\text {ice }}$, 
where $\phi$ is subglacial hydraulic potential, $z_{\text {bed }}$ is the WGS 84 elevation of the ice-bed interface, $h$ is the ice thickness in meters, $\rho_{\text {water }}=1000 \mathrm{~kg} \mathrm{~m}^{-3}$ is the density of fresh water, and $\rho_{\text {ice }}=917 \mathrm{~kg} \mathrm{~m}^{-3}$ is the density of glacial ice.

Equation (1) assumes that subglacial water pressure is at overburden pressure, fully supporting the column of ice above it, and neglects the effects of bridging stresses. Very few data exist for assessing how realistic these assumptions are. Measurements by Engelhardt and Kamb (1997) at the Siple Coast found basal pressures varying within a few percentage points of overburden. Idealized modeling by Dow et al. (2016) on a simple plane yielded pressure waves ranging from $95 \%$ to $104 \%$ of overburden pressure. In Greenland, where the basal water system can be connected to the atmosphere via moulins, analysis has used a wider range of subglacial water pressures (e.g., Chu et al., 2016, who considered values as low as $60 \%$ of overburden pressures).

This work uses laser-derived ice surface elevations and radar-derived ice thicknesses to calculate hydraulic potential along the profiles. Equation (1) can be refactored to separate the observations of the ice surface elevation and ice thickness:

$\phi=z_{\text {srf }} \rho_{\text {water }}-h\left(\rho_{\text {water }}-\rho_{\text {ice }}\right)$.

Since changes in surface elevation have $\sim 9$ times the impact on hydropotential gradients as changes to ice thickness, we use laser-derived surface elevations, which are more precise than those derived from radar. Profile data were gridded using the same approach as bed elevations.

Following standard propagation of errors for Eq. (2) and using the $\sigma_{\mathrm{h}}$ from Sect. 3.3.1 and $\sigma_{z_{\text {srf }}}$ from Sect. 3.2.1, the uncertainty is estimated to be $10 \mathrm{~m}$ of hydraulic head. However, this analysis does not include uncertainties due to the assumption that basal water pressure is equal to overburden or the fact that radar observations of bed elevation are likely to entirely miss narrow valleys since the radar itself is more likely to detect a first return from the side before a deeper return from the bed.

\subsubsection{Reflection coefficients}

The strong dielectric contrast between water and ice means that this reflection should be significantly brighter than one produced by ice and rock. This observation has been used in an attempt to identify subglacial water as early as Robin et al. (1969) and has been used frequently since (e.g., Oswald and Robin, 1973; Siegert et al., 1996; Carter et al., 2007).

The radar equation describes the amplitude of the returned signal at the antenna $\left(P_{\mathrm{r}}\right)$ in terms of system and environmental parameters (Peters et al., 2005) assuming a specularly reflecting interface:

$P_{\mathrm{r}}=P_{\mathrm{t}}\left(\frac{\lambda_{1}}{4 \pi}\right)^{2} \frac{G_{\mathrm{t}} G_{\mathrm{r}} T_{12}^{2} L_{\text {ice }}^{2}}{\left[2\left(h+z / n_{2}\right)\right]^{2}} R_{23}$, where $R_{23}$ is the ice-bed reflection coefficient that we are interested in. $T_{12}$ is the air-ice transmission coefficient. Transmitted power $\left(P_{\mathrm{t}}\right)$, antenna gain due to cross section $\left(\frac{\lambda_{1}}{4 \pi}\right)$, and the receiver and processing gains $\left(G_{\mathrm{t}}, G_{\mathrm{r}}\right)$ combine to determine the system gain. The geometric spreading loss

$L_{\mathrm{s}}=\left[\frac{1}{2\left(h+z / n_{2}\right)}\right]^{2}$

is a function of aircraft height above the ice surface $(h)$ and ice thickness $(z)$, both of which can be recovered directly from the interpreted radar data, along with the dielectric constant for glacial ice $\left(n_{2}=\sqrt{\epsilon}=1.78\right)$.

Finally, $L_{\text {ice }}$, the energy lost as an electromagnetic wave travels through a dielectric medium, is a function of its permittivity. For ice, this depends primarily on temperature and chemistry (Matsuoka, 2011). Across Antarctica, oneway depth-averaged dielectric ice loss $\left(N_{\mathrm{a}}\right)$ varies from 3 to $30 \mathrm{~dB} \mathrm{~km}^{-1}$ (Matsuoka et al., 2012). This wide variation in physically feasible values is the dominant source of uncertainty when calculating reflection coefficients.

Some studies attempt to determine $L_{\text {ice }}$ independently from the radar data, either deriving it from first principles based on modeled temperature profiles and salt content (Matsuoka et al., 2012) or extrapolating from measured properties at ice cores (MacGregor et al., 2007). Other studies estimate ice loss from the radar data: Peters et al. (2005) assumed that the brightest echoes correspond to water at the bed and that depth-averaged $L_{\text {ice }}$ is constant across the survey area; Jacobel et al. (2009) assumed that the distribution of reflection coefficients is independent of ice thickness and obtained $L_{\text {ice }}$ from the slope of ice thickness vs. geometry-corrected returned power. Recent work has refined these approaches to infer spatially varying patterns of dielectric ice loss across a survey at a resolution determined by the topographic variation (Schroeder et al., 2016a).

This paper does not attempt to use absolute reflection coefficients to verify the existence of water at the bed. Instead, they are used to compare relative bed properties under similar ice thicknesses. Absolute values would require calibration of the system gain (typically obtained both at the lab bench and by collecting data over open seawater) and validation to previous systems.

Given these goals, we modified the simplest approach of determining depth-averaged dielectric ice loss from the slope of geometry-corrected echo strengths vs. ice thicknesses. This approach relies on the assumption that basal reflection coefficients are independent of ice thickness, which is overly simplifying since basal temperature - and therefore the presence of water at the bed - is correlated with ice thickness. We see evidence of a slope change associated with the likely presence of water, so we restricted our linear regression to data in thinner ice. Since thinner ice is on average cooler than thicker ice, restricting the range of thicknesses used in the fit will result in an estimate that is a lower bound on dielectric ice loss. 


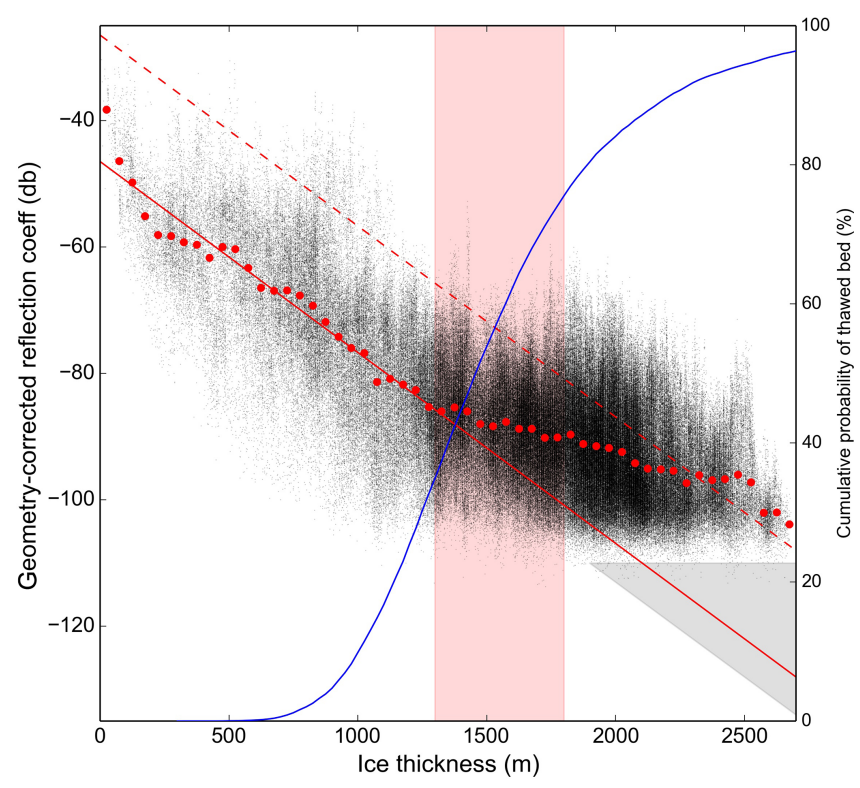

Figure 5. Geometry-corrected reflection coefficients vs. ice thickness for all bed picks in the survey. Red dots show the median reflection coefficient for $50 \mathrm{~m}$ wide ice thickness bins that were used in calculating the slope. The solid red line shows the slope for $-15.1 \mathrm{~dB} \mathrm{~km}^{-1}$ (one-way) based on calculations for ice thicknesses less than $1300 \mathrm{~m}$. The red rectangle shows the region where we assume that increased presence of water at the bed causes a broadening of the reflection coefficient distribution, and the gray triangle indicates the region where the signal-to-noise ratio could explain the absence of data. The dotted line has been shifted up $20 \mathrm{~dB}$ from the shallow-ice fit, representing the higher reflection coefficients expected if there is water at the bed. The blue line shows the cumulative probability of a thawed bed for a given ice thickness.

Figure 5 shows reflection coefficient data derived from peak power measurements from all KOPRI radar bed picks in the study region. In order to address the uneven distribution of samples across ice thicknesses, it also shows the median reflection coefficient for $50 \mathrm{~m}$ bins of ice thickness, which is the input used in calculating the linear regression.

At first glance, this does not appear to be a linear distribution; there is a higher slope for the thinner ice than for the thicker ice. It would be surprising if this were due to the distribution of dielectric losses since thinner ice is typically colder on average and thus has a lower dielectric ice loss. Instead, this distribution can be explained as a combination of the radar system's noise floor and changing basal properties with depth.

The observed geometry-corrected reflection coefficients have a minimum value of around $-110 \mathrm{~dB}$, which serves to cut off the linear distribution. There are areas where the bed can only be identified as a disturbance in the background noise. While the manually interpreted bed picks include these regions, their computed reflection coefficients are not valid. This threshold is not a hard limit because the noise distribu- tion varies from trace to trace. Additionally, the lower bound would be expected to have a slight positive slope due to the effects of correcting for spreading loss, which is apparent in the data.

Liquid water at the bed would be expected to increase the range of observed reflection coefficients, with a maximum value up to $20 \mathrm{~dB}$ above those observed on a dry bed. This can explain the observed widening and/or shift of the distribution at depths between 1300 and $1800 \mathrm{~m}$ since the existence of basal water typically requires the insulation provided by thicker ice. Due to the noise floor, a linear fit in this region will underestimate $L_{\text {icee }}$. However, the slope of the upper bound of the scatterplot at depths over $1700 \mathrm{~m}$ matches the average slope at depths under $1200 \mathrm{~m}$, which supports a roughly constant $L_{\text {ice. }}$.

Ice thickness required to reach the basal melting point can be estimated using the Robin model (Robin, 1955; Cuffey and Patterson, 2010), which is a 1D model that accounts for ice thickness, accumulation rate, surface temperature, geothermal flux, and basal heat generation. There are many degrees of freedom, and in an attempt to simplify and constrain the possible range of solutions, a Monte Carlo approach was adopted. The accumulation rate in ice equivalent was assumed to have a normal distribution with 1 standard deviation of $0.06 \pm 0.02 \mathrm{~m} \mathrm{a}^{-1}$ (van Wessem et al., 2014b). Geothermal flux was assumed to have a normal distribution of $0.06 \pm 0.01 \mathrm{~W} \mathrm{~m}^{-} 2$ (An et al., 2015). Surface temperature was assumed to have a normal distribution of $-35 \pm 5^{\circ} \mathrm{C}$ (van Wessem et al., 2014a). The standard deviation of the geothermal flux was expected to capture the effects of frictional heating of 0 to $0.01 \mathrm{~W} \mathrm{~m}^{-2}$, which is appropriate for up to $50 \mathrm{~m} \mathrm{yr}^{-1}$ of basal sliding (Rignot et al., 2017) with $10 \mathrm{kPa}$ of shear stress. A total of 20000 solutions were generated, and the resulting cumulative probabilities of a thawed bed are shown in Fig. 5. This analysis indicates that the transition of the bed from predominately frozen to predominately thawed occurs with a sufficient degree of likelihood across ice thicknesses consistent with the observed change in basal reflectivity slope.

In combination, these effects can explain the shape of the distribution of observed reflection coefficients vs. ice thicknesses shown in Fig. 5. Performing a linear regression with an upper limit on ice thickness of $1300 \mathrm{~m}$, where the basal water is hypothesized to start contributing, yields a one-way $L_{\text {ice }}=15.1 \mathrm{~dB} \mathrm{~km}^{-1}(\sigma=0.7)$, which should be a lower bound within the region.

\subsubsection{Specularity}

Reflection coefficients are problematic for characterizing the basal interface because they do not make it possible to separate the contribution of the dielectric contrast and spatially varying roughness. Specularity is another property of the radar return that can be informative and is appealing because it is both purely a geometrical property and dimensionless 


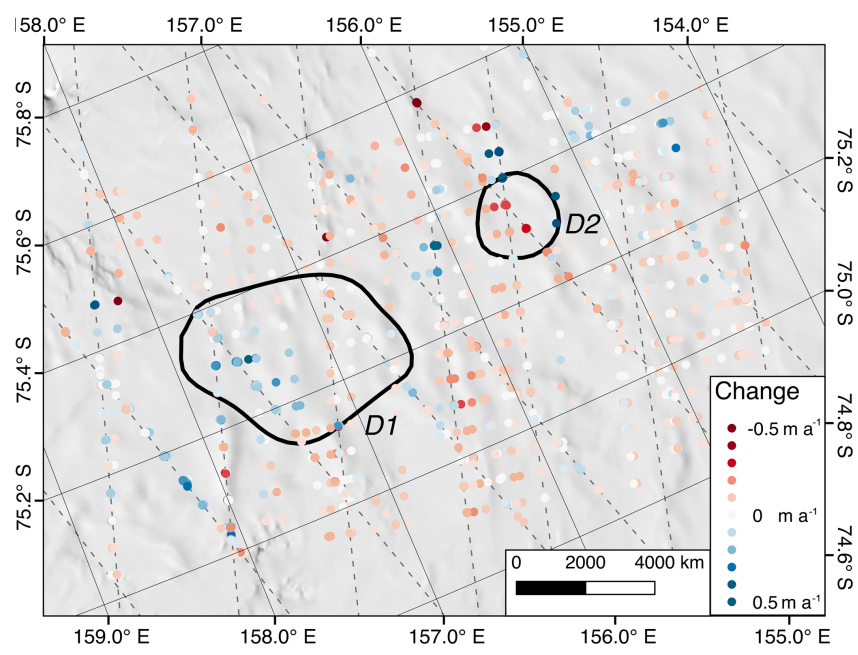

Figure 6. Difference between the 2017 KOPRI surface elevations and the 2004-2009 ICESat elevations, normalized by time between observations. Blue is rising; red is falling. Dashed lines are nominal ICESat ground tracks. The background image is the MODIS mosaic.

(the uncertainties introduced in an attempt to calculate absolute reflection coefficients cancel out). Conceptually, it describes how mirror-like a surface is: whether it reflects incident energy directly back or scatters it.

Searching for lakes based on the uniformity and specularity of their signal is not a new concept. It is similar to the old criteria regarding fading, which has been discussed since the initial deployment of ice-penetrating radar in Antarctica (Robin et al., 1969). Fading describes how much variation is observed along-track, where uniform surfaces are assumed to vary less than rough surfaces. Other attempts to quantify specularity have involved a proxy looking at the along-track, small-wavelength variation in reflection coefficient (Langley et al., 2011; Peters et al., 2005). More recently, Schroeder et al. (2015) defined specularity content $\left(S_{\mathrm{c}}\right)$ using the ratio between energy captured in focusing apertures of different lengths, building on the observation of Peters et al. (2007a) that different focusing apertures lead to roughness-dependent gains in the focused products. In this analysis, we compute specularity in the same way as Schroeder et al. (2015).

\section{Results}

\subsection{Lake stage}

Figure 6 shows the spatial distribution of time-normalized elevation changes as observed using crossings between GLAS lines and the new transects. Figure 7 shows elevation changes computed along individual profiles that followed GLAS ground tracks.

Both the crossovers (Fig. 6) and reflight data (Fig. 7) are consistent in showing that the downstream part of the D1 out- line (as defined by GL0194 and GL0158) has continued to rise, while the upstream portion is inconclusive.

While the region inside the original D2 outline appears to still be lowering with a total displacement of $\sim 5 \mathrm{~m}$, it borders an area along line GL0328 with up to $15 \mathrm{~m}$ of elevation gain since the ICESat era. There is a similar area that is also lowering on the south side of the large positive anomaly, and all three extrema are observed in both profile and intersection data. Note that the two points to the west of D2 where the surface appears to be rising are from a single unrepeated GLAS track, so there is no time series associated with them, and we do not consider them to be a reliable signal.

Unfortunately, this survey alone has been unable to address the $\frac{\mathrm{d} H}{\mathrm{~d} t}$ behavior in detail since the end of the ICESat era. However, there is no evidence that any of the Smith et al. (2009) lakes have switched from draining to filling or vice versa, and they have been established to be at a highstand relative to previous ICESat observations. Additionally, there is no evidence of an ice-dynamic-associated $\frac{\mathrm{d} H}{\mathrm{~d} t}$ signal in the David Glacier region when compared to ICESat data. That is, patterns of surface elevation lowering are not associated with surface velocities or their gradients.

\subsection{Hydraulic potential gradients}

Figure 8 shows gridded hydraulic potential over the survey. The most immediate observation in the new hydraulic potential map is that there is a ridge running through D1. This is consistent with surface observations of crevassing extending into D1, and it confirms that lake outlines based on interpolating between repeat-track surface elevation changes do not necessarily correspond to a large connected collection of water, which by definition would have to be at a constant potential. However, there is a broad low over the lower part of D1, which is consistent with the reinterpreted surface elevation record. Additionally, there is no clear potential minimum associated with the original D2 outline. Instead, this survey shows a small minimum to the south.

\subsection{Reflection coefficient}

Figure 9 shows the reflection coefficients that have been corrected for geometry and ice loss. While the highest reflection coefficients are in the main trunk of the glacier and found in areas of greater than $\sim 1700 \mathrm{~m}$ ice thickness, their distribution within those bounds is not obviously correlated with surface velocities or ice thicknesses. Instead, around lake D1, $P_{\mathrm{r}}$ tends to be higher in regions with lower gradients of hydraulic potential, consistent with water pooling. The region around lake D2 is more complicated, with bright beds corresponding to gradients of low hydraulic potential but not necessarily matching up with the observed surface deflections.

It is possible that a more sophisticated method of calculating the contribution of dielectric ice loss would lead to clearer results. Model-based approaches were not pursued: 

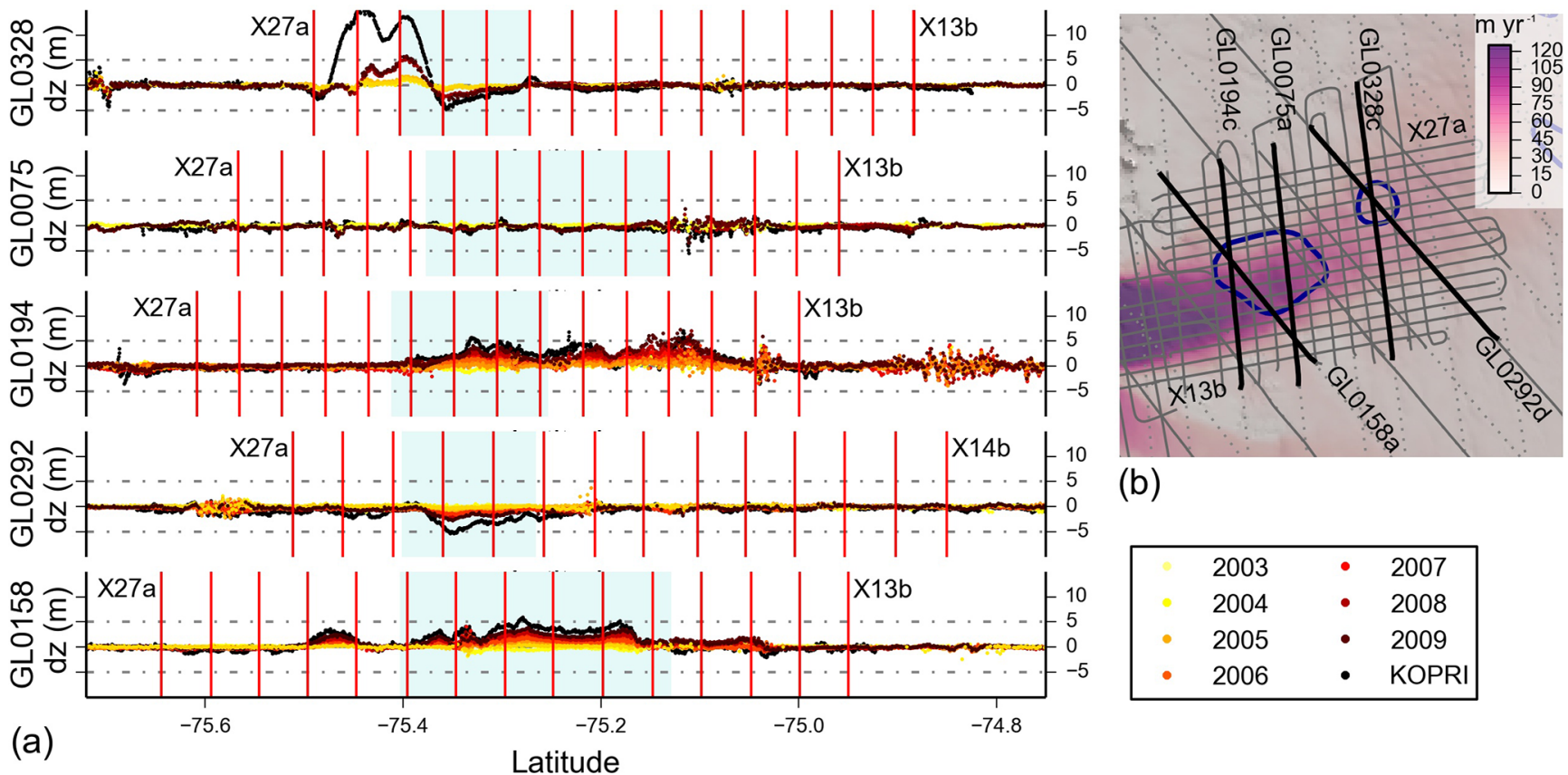

(b)

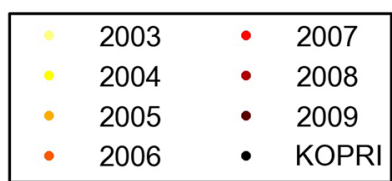

Figure 7. (a) Individual profiles for the GLAS reflights showing surface elevations with respect to modeled surface in 2005 . Vertical red lines show the intersections with the $X$ transects, and blue shading shows where the profiles intersect the Smith et al. (2009) lakes. (b) Context map showing locations of selected tracks. The background is the ice surface velocity (Rignot et al., 2011b).

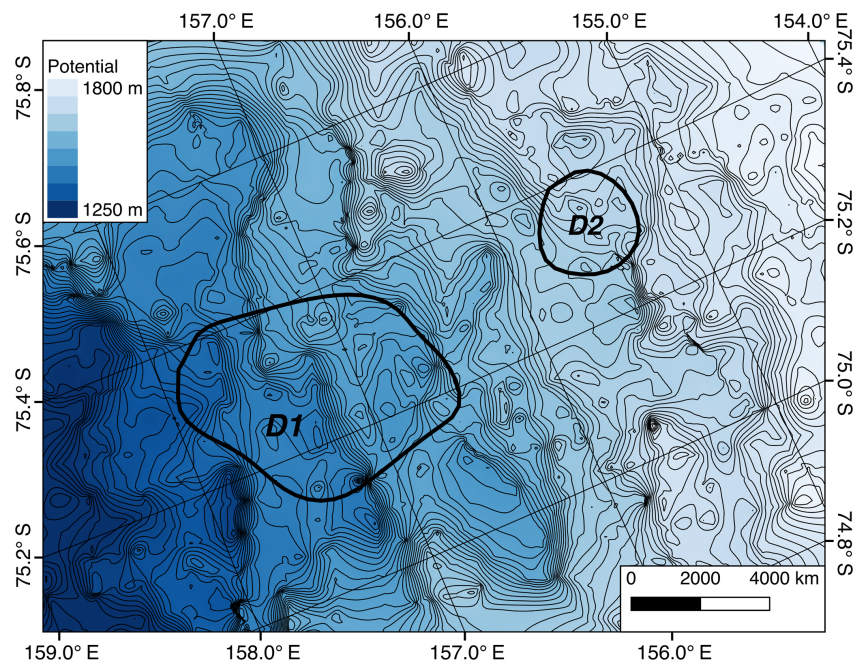

Figure 8. DEM showing hydraulic potential with $10 \mathrm{~m}$ contours for the region around lakes D1 and D2. The uncertainty is estimated to be at least $10 \mathrm{~m}$ of hydraulic head, or one small contour line.

the continent-wide model from Matsuoka et al. (2012) has insufficient resolution, and integrating a dynamic model with the new topography is beyond the scope of this paper.

We also note that the span of reflection coefficients is still larger than would be expected for typical materials and cannot be explained by contributions of dielectric ice loss alone. The analysis presented here uses the radar equation for spec- ular interfaces; a pure scattering interface would have a geometric spreading loss of $1 / r^{4}$ (Peters et al., 2005). Additionally, there could be englacial or surface terms not correlated with ice thickness that we are not accounting for. There is significant surface crevassing along the shear margins and over parts of D2, so correcting for surface scattering losses (Schroeder et al., 2016b) will likely yield an improvement in reflection coefficients. This topic warrants future investigation.

\subsection{Specularity}

Figure 10 shows the results of calculating specularity content over the lake region, plotted on top of the hydraulic potential contours. As with the reflection coefficient analysis, the regions of higher along-flow specularity are aligned with the regions of lower gradient. This is consistent with water collecting where it is flat and then being transported more efficiently under higher gradients. However, the clear anisotropy in the specularity signal is not characteristic of a typical radar lake, which would be expected to have an isotropically mirror-like surface (Young et al., 2016). Instead, we see higher specularity along-flow and lower across-flow.

\section{Discussion}

This paper presents results from a survey of lower David Glacier that includes surface elevation, subglacial topogra- 


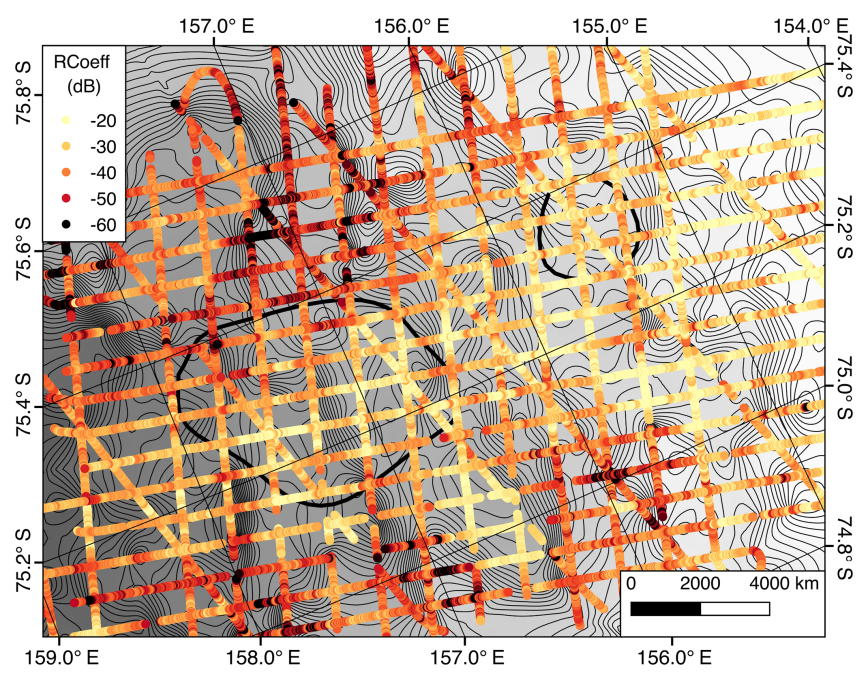

Figure 9. Relative reflection coefficients for the lake region, corrected for geometry and one-way dielectric losses of $15.1 \mathrm{~dB} \mathrm{~km}^{-1}$. The background consists of $10 \mathrm{~m}$ contours for hydraulic potential, with hypothesized lake locations outlined in black (Smith et al., 2009).

phy, and radar-derived boundary conditions of potential active subglacial lakes. Beyond providing first-order boundary conditions for modeling and for site selection for a drilling campaign, this paper uses the new surface elevation changes and grids of hydraulic potential to suggest new locations for the lakes and provides an initial look at the radar-derived basal properties that differentiate active lakes from traditional radar lakes.

\subsection{Reinterpretation of lake locations}

The Smith et al. (2009) classification of D1 was based on three lines, and D2 was based on a single line. Their paper does not specify which GLAS tracks were used, but based on the number of repeats for each track, D1's outline was presumably derived from GL0194, GL0158, and GL0039 but not GL0075, and D2 was based on GL0292 and not GL0328. Lines GL0075 and GL0328 would have been left out of the Smith et al. (2009) analysis due to having insufficient repeats for the determination of cross-track slope.

Based on the new ice thickness and hydraulic potential grids discussed in Sect. 3.3.2, an extension of the ICESat surface elevation record, and an understanding of the sparse data spacing involved in the original outlines (Smith et al., 2009), this paper concludes that the original D1 outline is transected by an across-flow ridge with only the downstream portion associated with a significant surface elevation change signal. Additionally, the potential lakes do not extend as far south as the original outline.

Figure 11 shows time-normalized surface elevation change and hydraulic potential. It can be seen that D2, which was thought to be draining, is instead on the edge of a previously unexamined region with significant surface uplift that is not consistent with the effects of ice dynamics. The area of maximum uplift is consistent with a local minimum in hydraulic potential to the south of the previous outline and is bracketed by areas of significant but smaller subsidence. We interpret these as all being part of the same feature, corresponding to water accumulation. The surface expression of basal changes is not straightforward to determine: Sergienko et al. (2007) modeled this for a draining lake and found an evolving, nonmonopole pattern.

The analysis in our paper is able to include GLAS data from lines with fewer repeats and pointed farther off the nominal tracks than Smith et al. (2009) could because the crossover analysis agrees with the profile-based comparisons, and none of the elevation change signals were correlated with cross-track distance or aircraft roll. So, instead of observing the larger elevation change, Smith et al. (2009) identified an outline for D2 based on a line that only crossed the bordering subsiding region. This caused them to infer an offset boundary from what we observe as well as classify it as draining instead of filling.

Our results do not show any evidence of the D1 or D2 features switching between filling and draining, but it cannot be ruled out by a single snapshot 7 years after the end of the GLAS era. Siegfried and Fricker (2018) used CryoSat2 in an effort to extend the surface altimetry record for a large subset of the lakes originally described by Smith et al. (2009), including David Glacier. They concluded that "smallmagnitude height-anomalies on these lakes were in-phase with small height-anomalies in the region outside the lake boundaries" while pointing out that CryoSat-2 data are challenging to interpret in this region due to surface roughness. Their analysis does not agree with our results, where we see clear evidence of concentrated surface elevation change. We attribute the difference to laser altimetry's higher precision, making it the preferred tool for this region.

This reclassification of the potential boundaries of D1 and D2 provides an illustration of the pitfalls inherent in attempting to study active lakes based purely on the Smith et al. (2009) polygons or to use them to assume basal boundary conditions of temperature or basal shear stress. As described in the original paper, lake outlines are interpolations based on data that are increasingly sparse farther north. This is particularly relevant for planning and interpreting surveys consisting of a single radar transect over an active lake; a traverse planned directly across the middle of D1 could easily have resulted in a transect crossing the region with gradients of high hydraulic potential and no evidence of collected basal water in any form, missing the smaller region that has gradients of low hydraulic potential and anisotropic specularity.

\subsection{Radar signature of active lakes}

Consistent with most other radar investigations of suspected active lakes (Welch et al., 2009; Wright et al., 2014; Lang- 

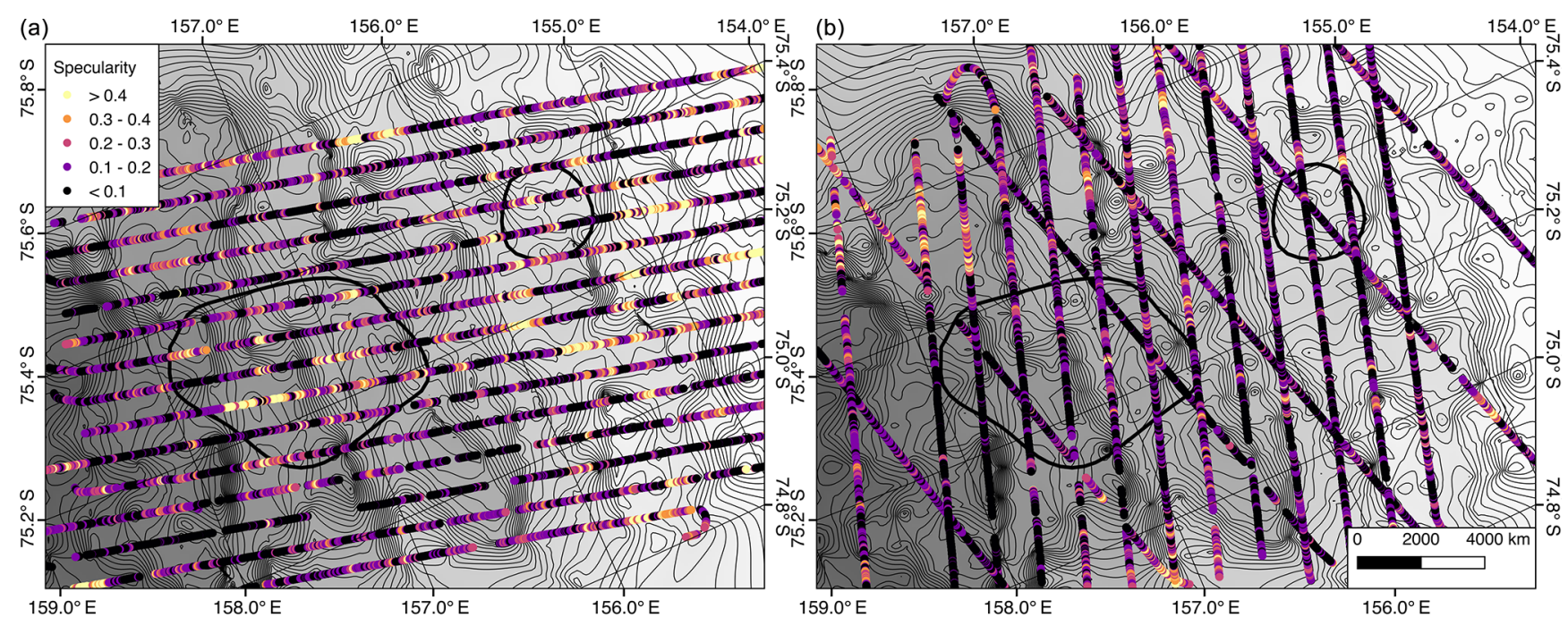

Figure 10. Specularity along- (a) and across-flow (b) of the main trunk. The background is the same as Fig. 9.

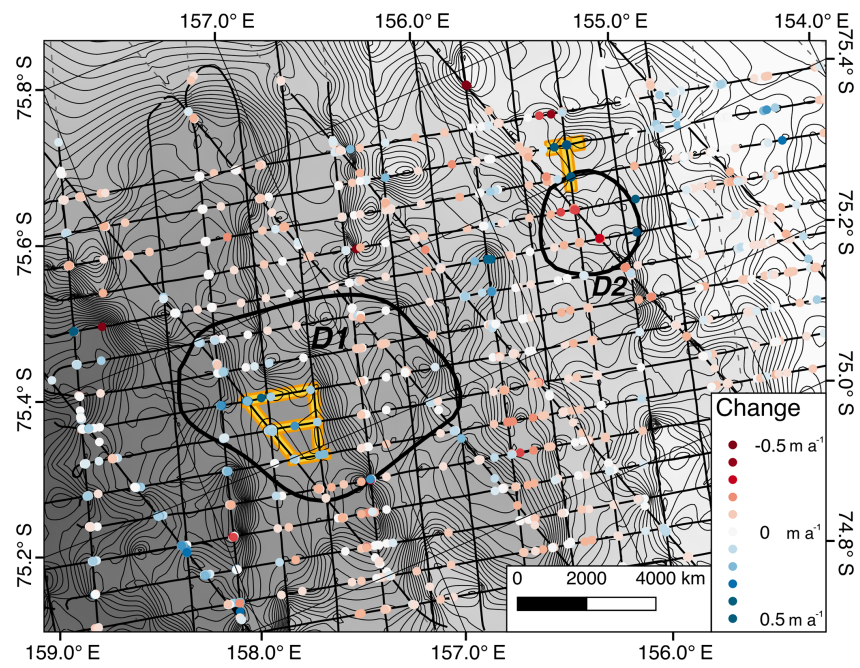

Figure 11. Observed time-normalized surface elevation changes are plotted on a DEM showing hydraulic potential with $10 \mathrm{~m}$ contours for the region around lakes D1 and D2. Transect segments where this study observed correspondence between a hydraulic potential minimum and a time history of surface elevation change are highlighted in yellow.

ley et al., 2011), the D1 and D2 surface features are not associated with the relatively bright and isotropically specular signature of a classic radar lake. There are three possible explanations for this mismatch: surveys are looking for water in the wrong place, at the wrong time, or using the wrong features in the radargram. Previous investigations consisting of a single line could be explained by the complicated transfer function from basal changes to surface expression or by the uncertainty in the lake outlines. Other surveys that did not include surface elevation measurements could be explained by hypothesizing that the active lake was at a lowstand. How- ever, the laser altimetry presented here shows that both D1 and D2 are at an even higher stand than during the ICESat era, so inconclusive results cannot be explained as being due to drained lakes, and the spatial extent and density of the survey make it unlikely to have entirely missed the lakes. Thus, we conclude that active lakes cannot be expected to share the distinguishing physical features of radar lakes.

In interpreting reflection coefficients, there are a number of possibly complicating factors. In an active lake system, it is likely that there are significant portions of the bed at the pressure melting point, which would lead to lower contrast between the ice-water interface and the ice-bed interface. Depending on the depth of the lake, the roughness of the water-rock interface, and the salinity of its water, it is also possible that the radar return from the water-rock interface could interfere with that from the ice-water interface, lowering the observed reflection coefficient (MacGregor et al., 2011). Christianson et al. (2016) investigated anomalously low reflection coefficients in a region just offshore of the Whillans Ice Stream grounding zone and concluded that they were due at least in part to sediments entrained in the ice that had not yet melted out. Similarly, we could consider active lakes to be at one end of a continuum, where stable radar lakes are at the other end, and they are primarily differentiated by their water residence times. The more rapidly evolving features may not have existed for long enough to melt a smooth roof, so we could be observing the preserved imprint of the bed at lowstands or basal roughness advected from upstream of the lake. Supporting this view, some active lakes (Adventure Subglacial Trench) do appear in classic lake inventories, but they are typically the ones farther upstream, with longer cycle times.

Specularity is an appealing complement to reflection coefficient analysis for characterizing the basal interface. A classic lake would be expected to have a smooth, flat ice- 
water interface and appears as an isotropically specular surface, which requires decimeter-scale smoothness over hundreds of meters. This concept has been used in earlier work to characterize the distribution of subglacial water: Young et al. (2016) looked at the anisotropy of individual lines by comparing the specularity of the first return to the amount of scattering recorded afterward, while Schroeder et al. (2013) leveraged a gridded survey of Thwaites Glacier. Schroeder et al. (2013) reported a pattern of anisotropic specularity in Thwaites Glacier and concluded that it indicates "canals" of subglacial water pooling, aligned with the ice flow. Since canals require a sedimentary subglacial interface, this is consistent with both the hypothesis of Carter et al. (2017) that active subglacial lakes drain through canals and with the observations of Smith et al. (2017) of active lakes in the region of Thwaites Glacier where Schroeder et al. (2013) identified the water system transition. In the David Lakes region, we see an overall pattern of anisotropic specularity, including over the regions of surface elevation change, that is similar to that seen in Thwaites. Further work is needed to understand the overall hydrologic systems driving these active lakes, and the anisotropic specularity in this region provides an interesting constraint on possible organizations of water.

\section{Conclusions}

This paper describes a new aerogeophysical dataset focusing on the two most downstream active subglacial lakes on David Glacier. The primary sensors were a laser altimeter and icepenetrating radar. In combination, these collected data allow a determination of the surface elevation changes relative to the ICESat era, a higher-resolution map of subglacial bed elevation, and the first radar-derived characterization of this region's ice-bed interface.

First, comparing new laser altimeter surface elevations to the ICESat record shows that the original Smith et al. (2009) lake outlines require refinement (Fig. 6). The most downstream lake (D1) has continued to fill, but its extent is probably smaller than the original outline. The second-most downstream lake (D2) was originally classified as draining. However, the new surface elevation data reveal a larger anomaly adjacent to the original D2 outline. This anomaly appears to be a filling lake, and D2 appears to be an edge effect.

Next, ice-penetrating radar data were used to estimate the basal hydraulic potential in the David Lakes region. Lake D1 is divided by a clear hydraulic potential ridge, with the downstream portion corresponding to the largest area of surface elevation change. The upstream part of D1 has a loweramplitude surface elevation signal, primarily appearing in the profile data. Additionally, there are nearby areas of hydraulic potential minima that do not appear to have a surface elevation signal. The story around D2 is less clear, but the highestamplitude surface elevation changes appear to be associated with a shallow hydraulic potential minimum.
Traditionally, the basal reflection coefficient has been a primary tool in identifying subglacial water. This paper attempted to sidestep the well-known pitfalls inherent in calculating absolute basal reflection coefficients and instead focused on selecting a dielectric ice loss that would lead to acceptable uncertainties in the relative reflection coefficients. Consistent with previous radar surveys of active lakes, neither D1 nor D2 would be categorized as a classic radar lake on the basis of relative reflection coefficients. There is a weak correspondence between regions with gradients of low hydraulic potential and elevated basal reflection coefficients, but the association is inconclusive, and the results neither confirm nor rule out the existence of concentrated subglacial water. In the case of active lakes, this would make sense if they are part of a distributed water system on a wet bed.

Finally, we looked at the specularity content of the basal interface. Rather than being isotropically specular as would be expected for an extensive subglacial lake, it is anisotropically specular, with high specularity occurring along-flow. Both the specularity and reflection coefficient signals are strongest near the lower portion of lake D1, while the region around D2 is more ambiguous, with high reflection coefficients and anisotropic specularity distributed across the glacier's trunk. The anisotropic specularity seen here is similar to observations on Thwaites Glacier in the region of its newly discovered active lakes. This radar signature could be consistent either with water accumulating in linearly organized features or with the active lakes' roofs retaining the imprint of the deflated state even as they are filling.

Data availability. All profile-based data have been released via Zenodo. The radargrams are available in Lee et al. (2020a), and the ice thickness, surface elevation, bed elevation, and positioning data products are available in Lee et al. (2020b).

Author contributions. The study was conceptualized by LEL, DAY, LHB, DDB, C-KL, WSL, JIL, and JL, with funding acquired by DDB, C-KL, WSL, JIL, and JL. The investigation was completed by LEL and EQ. Methodology was developed by LEL and DAY. Formal analysis was completed by LEL, LHB, and DAY, with visualization by LEL and LHB. Data curation was completed by DAY and LHB. All authors contributed to writing.

Competing interests. The authors declare that they have no conflict of interest.

Acknowledgements. The authors would like to thank Helicopters New Zealand pilot Phil Robinson and engineer Fred Wunderler for their support and dedication to this project. Dillion Buhl, Tom Richter, Greg Ng, and Scott Kempf provided invaluable engineering, technical, and field support. LEL would like to thank Ben Smith and Luke Voss for productive conversations about ICESat analy- 
sis and reflection coefficients. We thank Joseph MacGregor and Nicholas Holschuh for their thoughtful and constructive reviews. This is UTIG contribution 3647.

Financial support. We acknowledge the support of the G. Unger Vetlesen Foundation. Laura E. Lindzey was partially supported by the UTIG Ewing-Worzel Fellowship and the Gale White Endowed Fellowship in Geophysics. Won Sang Lee and Choon-Ki Lee were supported by research grants from the Korean Ministry of Oceans and Fisheries (grant nos. KIMST20190361 and PM19020). Jong Ik Lee was supported by a research grant from the Korea Polar Research Institute (grant no. PE20020). Joohan Lee was supported by a research grant from the Korea Polar Research Institute (grant no. PE20050).

Review statement. This paper was edited by Etienne Berthier and reviewed by Nicholas Holschuh and Joseph MacGregor.

\section{References}

An, M., Wiens, D. A., Zhao, Y., Nyblade, A. A., Kanao, M., Li, Y., Maggi, A., and Leveque, J.-J.: Temperature, lithosphereasthenosphere boundary, and heat flux beneath the Antarctic Plate inferred from seismic velocities, J. Geophys. Res.-Sol. Earth, 120, 8720-5742, https://doi.org/10.1002/2015JB011917, 2015.

Bindschadler, R., Choi, H., Wichlacz, A., Bingham, R., Bohlander, J., Brunt, K., Corr, H., Drews, R., Fricker, H., Hall, M., Hindmarsh, R., Kohler, J., Padman, L., Rack, W., Rotschky, G., Urbini, S., Vornberger, P., and Young, N.: Getting around Antarctica: new high-resolution mappings of the grounded and freely-floating boundaries of the Antarctic ice sheet created for the International Polar Year, The Cryosphere, 5, 569-588, https://doi.org/10.5194/tc-5-569-2011, 2011.

Blankenship, D. D., Morse, D. L., Finn, C. A., Bell, R. E., Peters, M. E., Kempf, S. D., Hodge, S. M., Studinger, M., Behrendt, J. C., and Brozena, J. M.: Geologic controls on the initiation of rapid basal motion for West Antarctic ice streams: A geophysical perspective including new airborne radar sounding and laser altimetry results, The West Antarctic Ice Sheet: Behavior and Environment, Ant. Res. Ser., 77, 105-121, https://doi.org/10.1029/AR077p0105, 2001.

Blankenship, D. D., Kempf, S. D., Young, D. A., Richter, T. G., Schroeder, D. M., Greenbaum, J. S., van Ommen, T. D., Warner, R. C., Roberts, J. L., Young, N. W., Lemeur, E., Siegert, M. J., and Holt, J. W.: IceBridge HiCARS 1 L1B Time-Tagged Echo Strength Profiles, Version 1, NASA National Snow and Ice Data Center Distributed Active Archive Center, https://doi.org/10.5067/W2KXX0MYNJ9G, 2017a.

Blankenship, D. D., Kempf, S. D., Young, D. A., Richter, T. G., Schroeder, D. M., Ng, G., Greenbaum, J. S., van Ommen, T. D., Warner, R. C., Roberts, J. L., Young, N. W., Lemeur, E., and Siegert, M. J.: IceBridge HiCARS 2 L1B Time-Tagged Echo Strength Profiles, Version 1, NASA National Snow and Ice Data Center Distributed Active Archive Center, Boulder, Colorado USA, https://doi.org/10.5067/0I7PFBVQOGO5, 2017b.
Carter, S. P., Blankenship, D. D., Peters, M. E., Young, D. A., Holt, J. W., and Morse, D. L.: Radar-based subglacial lake classification in Antarctica, Geochem. Geophys. Geosyst., 8, Q03016, https://doi.org/10.1029/2006GC001408, 2007.

Carter, S. P., Blankenship, D. D., Young, D. A., and Holt, J. W.: Using radar-sounding data to identify the distribution and sources of subglacial water: application to Dome C, East Antarctica, J. Glaciol., 55, 1025-1040, https://doi.org/10.3189/002214309790794931, 2009.

Carter, S. P., Fricker, H. A., and Siegfried, M. R.: Antarctic subglacial lakes drain through sediment-floored canals: theory and model testing on real and idealized domains, The Cryosphere, 11, 381-405, https://doi.org/10.5194/tc-11-381-2017, 2017.

Castelletti, D., Schroeder, D. M., Hensley, S., Grima, C., Ng, G., Young, D. A., Gim, Y., Bruzzone, L., Moussessian, A., and Blankenship, D. D.: An Interferometric Approach to Cross-Track Clutter Detection in Two Channel VHF Radar Sounders, IEEE Trans. Geosci. Remote Sens., 55, 6128-6140, https://doi.org/10.1109/TGRS.2017.2721433, 2017.

Christianson, K., Jacobel, R. W., Horgan, H. J., Anandakrishnan, S., and Alley, R. B.: Subglacial Lake Whillans - Ice-penetrating radar and GPS observations of a shallow active reservoir beneath a West Antarctic ice stream, Earth Planet. Sci. Lett., 331-332, 237-245, https://doi.org/10.1016/j.eps1.2012.03.013, 2012.

Christianson, K., Jacobel, R. W., Horgan, H. J., Alley, R. B., Anandakrishnan, S., Holland, D. M., and Dallasanta, K. J.: Earth Surface Basal conditions at the grounding zone of Whillans Ice Stream, West Antarctica, from icepenetrating radar, J. Geophys. Res.-Earth Surf., 121, 1954-1983, https://doi.org/10.1002/2015JF003806, 2016.

Chu, W., Schroeder, D. M., and Seroussi, H.: Extensive winter subglacial water storage beneath the Greenland Ice Sheet, Geophys. Res. Lett., 43, 12484-12492, https://doi.org/10.1002/2016GL071538, 2016.

Cuffey, K. M. and Patterson, W. S. B.: The Physics of Glaciers, Butterworth-Heinemann, ISBN 978-0-12-369461-4, 2010.

Dow, C. F., Werder, M. A., Nowicki, S., and Walker, R. T.: Modeling Antarctic subglacial lake filling and drainage cycles, The Cryosphere, 10, 1381-1393, https://doi.org/10.5194/tc-10-13812016, 2016.

Engelhardt, H. and Kamb, B.: Basal hydraulic system of a West Antartic ice stream: constraints from borehole observations, J. Glaciol., 43, 207-230, https://doi.org/10.3189/S0022143000003166, 1997.

Fretwell, P., Pritchard, H. D., Vaughan, D. G., Bamber, J. L., Barrand, N. E., Bell, R., Bianchi, C., Bingham, R. G., Blankenship, D. D., Casassa, G., Catania, G., Callens, D., Conway, H., Cook, A. J., Corr, H. F. J., Damaske, D., Damm, V., Ferraccioli, F., Forsberg, R., Fujita, S., Gim, Y., Gogineni, P., Griggs, J. A., Hindmarsh, R. C. A., Holmlund, P., Holt, J. W., Jacobel, R. W., Jenkins, A., Jokat, W., Jordan, T., King, E. C., Kohler, J., Krabill, W., Riger-Kusk, M., Langley, K. A., Leitchenkov, G., Leuschen, C., Luyendyk, B. P., Matsuoka, K., Mouginot, J., Nitsche, F. O., Nogi, Y., Nost, O. A., Popov, S. V., Rignot, E., Rippin, D. M., Rivera, A., Roberts, J., Ross, N., Siegert, M. J., Smith, A. M., Steinhage, D., Studinger, M., Sun, B., Tinto, B. K., Welch, B. C., Wilson, D., Young, D. A., Xiangbin, C., and Zirizzotti, A.: Bedmap2: improved ice bed, surface and 
thickness datasets for Antarctica, The Cryosphere, 7, 375-393, https://doi.org/10.5194/tc-7-375-2013, 2013.

Fricker, H. A. and Scambos, T. A.: Connected subglacial lake activity on lower Mercer and Whillans Ice Streams, West Antarctica, 2003-2008, J. Glaciol., 55, 303-315, https://doi.org/10.3189/002214309788608813, 2009.

Fricker, H. A., Scambos, T. A., Bindschadler, R. A., and Padman, L.: An active subglacial water system in West Antarctica mapped from space, Science, 315, 1544-1548, https://doi.org/10.1126/science.1136897, 2007.

Fricker, H. A., Carter, S. P., Bell, R. E., and Scambos, T. A.: Active lakes of Recovery Ice Stream, East Antarctica: A bedrockcontrolled subglacial hydrological system, J. Glaciol., 60, 10151030, https://doi.org/10.3189/2014JoG14J063, 2014.

Gray, L., Joughin, I., Tulaczyk, S., Spikes, V. B., Bindschadler, R. A., and Jezek, K.: Evidence for subglacial water transport in the West Antarctic Ice Sheet through three-dimensional satellite radar interferometry, Geophys. Res. Lett., 32, L03501, https://doi.org/10.1029/2004GL021387, 2005.

Holt, J. W., Blankenship, D. D., Morse, D. L., Young, D. A., Peters, M. E., Kempf, S. D., Richter, T. G., Vaughan, D. G., and Corr, H. F. J.: New boundary conditions for the West Antarctic Ice Sheet: Subglacial topography of the Thwaites and Smith glacier catchments, Geophys. Res. Lett., 33, L09502, https://doi.org/10.1029/2005GL025561, 2006.

Hunter, J. D.: Matplotlib: A 2D graphics environment, Comput. Sci. Eng., 9, 90-95, https://doi.org/10.1109/MCSE.2007.55, 2007.

Jacobel, R. W., Welch, B. C., Osterhouse, D., Petttersson, R., and MacGregor, J. A.: Spatial variation of radar-derived basal conditions on Kamb Ice Stream, West Antarctica, Ann. Glaciol., 50, 10-16, https://doi.org/10.3189/172756409789097504, 2009.

Jamieson, S. S. R., Ross, N., Greenbaum, J. S., Young, D. A., Aitken, A. R. A., Roberts, J. L., Blankenship, D. D., and Siegert, M. J.: An extensive subglacial lake and canyon system in Princess Elizabeth Land, East Antarctica, Geology, 44, 87-90, https://doi.org/10.1130/G37220.1, 2016.

Kapitsa, A. P., Ridley, J. K., Robin, G. d. Q., Siegert, M. J., and Zotikov, I. A.: A large deep freshwater lake beneath the ice of central East Antarctica, Nature, 381, 684-686, https://doi.org/10.1038/381684a0, 1996.

Langley, K., Kohler, J., Matsuoka, K., Sinisalo, A., Scambos, T. A., Neumann, T., Muto, A., Winther, J. G., and Albert, M.: Recovery Lakes, East Antarctica: Radar assessment of sub-glacial water extent, Geophys. Res. Lett., 38, L05501, https://doi.org/10.1029/2010GL046094, 2011.

Lee, W. S., Lee, J. I., Lindzey, L. E., Beem, L. H., Young, D. A., Quartini, E., Blankenship, D. D., Lee, C.-K., Lee, J., and Kempf, S. D.: Radar observations of an active subglacial lake system in the David Glacier catchment, Antarctica, Zenodo, https://doi.org/10.5281/zenodo.3874655, 2020a.

Lee, W. S., Lee, J. I., Lindzey, L. E., Beem, L. H., Young, D. A., Quartini, E., Blankenship, D. D., Lee, C.-K., Lee, J., and Kempf, S. D.: Aerogeophysical characterization of an active subglacial lake system in the David Glacier catchment, Antarctica (Version 1.0.0), Zenodo, https://doi.org/10.5281/zenodo.3778452, $2020 \mathrm{~b}$.

MacGregor, J. A., Winebrenner, D. P., Conway, H., Matsuoka, K., Mayewski, P. A., and Clow, G. D.: Modeling englacial radar attenuation at Siple Dome, West Antarctica, using ice chemistry and temperature data, J. Geophys. Res.-Earth Surf., 112, F03008, https://doi.org/10.1029/2006JF000717, 2007.

MacGregor, J. A., Anandakrishnan, S., Catania, G. A., and Winebrenner, D. P.: The grounding zone of the Ross Ice Shelf, West Antarctica, from ice-penetrating radar, J. Glaciol., 57, 917-928, https://doi.org/10.3189/002214311798043780, 2011.

Matsuoka, K.: Pitfalls in radar diagnosis of ice-sheet bed conditions: Lessons from englacial attenuation models, Geophys. Res. Lett., 38, L05505, https://doi.org/10.1029/2010GL046205, 2011.

Matsuoka, K., MacGregor, J. A., and Pattyn, F.: Predicting radar attenuation within the Antarctic ice sheet, Earth Planet. Sci. Lett., 359-360, 173-183, https://doi.org/10.1016/j.epsl.2012.10.018, 2012.

Matsuoka, K., Skoglund, A., and Roth, G.: Quantarctica, Norwegian Polar Institute, https://doi.org/10.21334/npolar.2018.8516e961, 2018.

Moussessian, A., Jordan, R. L., Rodriguez, E., Safaeinili, A., Atkins, T. L., Edelstein, W. N., Kim, Y., and Gogineni, S. P.: A New Coherent Radar for Ice Sounding in Greenland, in: Geoscience and Remote Sensing Symposium (IGARSS), 484-486, https://doi.org/10.1109/IGARSS.2000.861604, 2000.

Oswald, G. K. A. and Robin, G. d. Q.: Lakes beneath the Antarctic Ice Sheet, Nature, 245, 251-254, https://doi.org/10.1038/245251a0, 1973.

Paterson, W. S. B.: Physics of Glaciers, Pergamon Press, 3rd edn., 1994.

Pattyn, F.: Antarctic subglacial conditions inferred from a hybrid ice sheet/ice stream model, Earth Planet. Sci. Lett., 295, 451-461, https://doi.org/10.1016/j.epsl.2010.04.025, 2010.

Peters, M. E., Blankenship, D. D., and Morse, D. L.: Analysis techniques for coherent airborne radar sounding: Application to West Antarctic ice streams, J. Geophys. Res.-Solid Earth, 110, B06303, https://doi.org/10.1029/2004JB003222, 2005.

Peters, M. E., Blankenship, D. D., Carter, S. P., Kempf, S. D., Young, D. A., and Holt, J. W.: Along-track focusing of airborne radar sounding data from West Antarctica for improving basal reflection analysis and layer detection, IEEE Trans. Geosci. Remote Sens., 45, 2725-2736, https://doi.org/10.1109/TGRS.2007.897416, 2007a.

Peters, M. E., Blankenship, D. D., Smith, D. E., Holt, J. W., and Kempf, S. D.: The distribution and classification of bottom crevasses from radar sounding of a large tabular iceberg, IEEE Geosci. Remote Sens. Lett., 4, 142-146, https://doi.org/10.1109/LGRS.2006.887057, 2007b.

QGIS.org: QGIS Geographic Information System. Open Source Geospatial Foundation Project, available at: http://qgis.osgeo. org, last access: 2016.

Rignot, E.: Mass balance of East Antarctic glaciers and ice shelves from satellite data, Ann. Glaciol., 34, 217-227, https://doi.org/10.3189/172756402781817419, 2002.

Rignot, E., Mouginot, J., and Scheuchl, B.: Antarctic grounding line mapping from differential satellite radar interferometry, Geophys. Res. Lett., 38, L10504, https://doi.org/10.1029/2011GL047109, 2011a.

Rignot, E., Mouginot, J., and Scheuchl, B.: Ice flow of the Antarctic ice sheet, Science, 333, 1427-1430, https://doi.org/10.1126/science.1208336, 2011 b.

Rignot, E., Mouginot, J., and Scheuchl, B.: MEaSUREs InSARBased Antarctica Ice Velocity Map, Version 2, NASA National 
Snow and Ice Data Center Distributed Active Archive Center, https://doi.org/10.5067/D7GK8F5J8M8R, 2017.

Robin, G. d. Q., Evans, S., and Bailey, J. T.: Interpretation of radio echo sounding in polar ice sheets, Philos. Trans. Roy. Soc. London A, 265, 437-505, https://doi.org/10.1098/rsta.1969.0063, 1969.

Robin, G. de Q.: Ice Movement and Temperature Distribution in Glaciers and Ice Sheets, J. Glaciol., 2, 523-532, https://doi.org/10.3189/002214355793702028, 1955.

Scambos, T. A., Haran, T. M., Fahnestock, M. A., Painter, T. H., and Bohlander, J.: MODIS-based Mosaic of Antarctica (MOA) data sets: Continent-wide surface morphology and snow grain size, Remote Sens. Environ., 111, 242-257, https://doi.org/10.1016/j.rse.2006.12.020, 2007.

Scambos, T. A., Berthier, E., and Shuman, C. A.: The triggering of subglacial lake drainage during rapid glacier drawdown: Crane Glacier, Antarctic Peninsula, Ann. Glaciol., 52, 74-82, https://doi.org/10.3189/172756411799096204, 2011.

Schroeder, D. M., Blankenship, D. D., and Young, D. A.: Evidence for a water system transition beneath Thwaites Glacier, West Antarctica, P. Natl. Acad. Sci. USA, 110, 12225-12228, https://doi.org/10.1073/pnas.1302828110, 2013.

Schroeder, D. M., Blankenship, D. D., Raney, R. K., and Grima, C.: Estimating subglacial water geometry using radar bed echo specularity: Application to Thwaites Glacier, West Antarctica, IEEE Geosci. Remote Sens. Lett., 12, 443-447, https://doi.org/10.1109/LGRS.2014.2337878, 2015.

Schroeder, D. M., Seroussi, H., Chu, W., and Young, D. A.: Adaptively constraining radar attenuation and temperature across the Thwaites Glacier catchment using bed echoes, J. Glaciol., 62, 1075-1082, https://doi.org/10.1017/jog.2016.100, 2016a.

Schroeder, D. M., Grima, C., and Blankenship, D. D.: Evidence for variable grounding-zone and shear-margin basal conditions across Thwaites Glacier, West Antarctica, Geophysics, 81, WA35-WA43, https://doi.org/10.1190/geo2015-0122.1, 2016.

Sergienko, O. V., MacAyeal, D. R., and Bindschadler, R. A.: Causes of sudden, short-term changes in icestream surface elevation, Geophys. Res. Lett., 34, 1-6, https://doi.org/10.1029/2007GL031775, 2007.

Siegert, M. J., Dowdeswell, J. A., Gorman, M. R., and Mcintyre, N. F.: An inventory of Antarctic sub-glacial lakes, Antarct. Sci., 8, 281-286, https://doi.org/10.1017/S0954102096000405, 1996.

Siegert, M. J., Carter, S., Tabacco, I., Popov, S., Blankenship, D. D., John, A., and Jackson, K. G.: A revised inventory of Antarctic subglacial lakes, Antarct. Sci., 17, 453-460, https://doi.org/10.1017/S0954102005002889, 2005.

Siegert, M. J., Ross, N., Corr, H., Smith, B., Jordan, T., Bingham, R. G., Ferraccioli, F., Rippin, D. M., and Le Brocq, A.: Boundary conditions of an active West Antarctic subglacial lake: implications for storage of water beneath the ice sheet, The Cryosphere, 8, 15-24, https://doi.org/10.5194/tc-8-15-2014, 2014.

Siegfried, M. R. and Fricker, H. A.: Thirteen years of subglacial lake activity in Antarctica from multi-mission satellite altimetry, Ann. Glaciol., 59, 42-55, https://doi.org/10.1017/aog.2017.36, 2018.

Siegfried, M. R., Fricker, H. A., Carter, S. P., and Tulaczyk, S.: Episodic ice velocity fluctuations triggered by a subglacial flood in West Antarctica, Geophys. Res. Lett., 43, 2640-2648, https://doi.org/10.1002/2016GL067758, 2016.
Skou, N. and Søndergaard, F.: Radioglaciology. A $60 \mathrm{MHz}$ ice sounder system., Tech. rep., Technical University of Denmark, 1976.

Smith, B. E., Fricker, H. A., Joughin, I. R., and Tulaczyk, S.: An inventory of active subglacial lakes in Antarctica detected by ICESat (2003-2008), J. Glaciol., 55, 573-595, https://doi.org/10.3189/002214309789470879, 2009.

Smith, B. E., Gourmelen, N., Huth, A., and Joughin, I.: Connected subglacial lake drainage beneath Thwaites Glacier, West Antarctica, The Cryosphere, 11, 451-467, https://doi.org/10.5194/tc11-451-2017, 2017.

Stearns, L. A., Smith, B. E., and Hamilton, G. S.: Increased flow speed on a large East Antarctic outlet glacier caused by subglacial floods, Nat. Geosci., 1, 827-831, https://doi.org/10.1038/ngeo356, 2008.

Tulaczyk, S., Mikucki, J. A., Siegfried, M. R., Priscu, J. C., Barcheck, C. G., Beem, L. H., Behar, A., Burnett, J., Christner, B. C., Fisher, A. T., Fricker, H. A., Mankoff, K. D., Powell, R. D., Rack, F., Sampson, D., Scherer, R. P., Schwartz, S. Y., Wissard, T. H. E., and Team, S.: WISSARD at Subglacial Lake Whillans, West Antarctica: scientific operations and initial observations, Ann. Glaciol., 55, 51-58, https://doi.org/10.3189/2014AoG65A009, 2014.

Van Liefferinge, B., Pattyn, F., Cavitte, M. G. P., Karlsson, N. B., Young, D. A., Sutter, J., and Eisen, O.: Promising Oldest Ice sites in East Antarctica based on thermodynamical modelling, The Cryosphere, 12, 2773-2787, https://doi.org/10.5194/tc-122773-2018, 2018.

van Wessem, J. M., Reijmer, C. H., Lenaerts, J. T. M., van de Berg, W. J., van den Broeke, M. R., and van Meijgaard, E.: Updated cloud physics in a regional atmospheric climate model improves the modelled surface energy balance of Antarctica, The Cryosphere, 8, 125-135, https://doi.org/10.5194/tc-8-125-2014, 2014.

van Wessem, J. M., Reijmer, C. H., Morlighem, M.. Mouginot, J.. Rignot, E., Medley, B., Joughin, I., Wouters, B., Depoorter, M. A., Bamber, J. L., Lenaerts, J. T. M., van de Berg, W. J., van den Broeke, M. R., and van Meijgaard, E.: Improved representation of East Antarctic surface mass balance in a regional atmospheric climate model, J. Glaciol., 60, 761-770, https://doi.org/10.3189/2014JoG14J051, 2014b.

Welch, B. C., Jacobel, R. W., and Arcone, S. A.: First results from radar profiles collected along the US-ITASE traverse from Taylor Dome to South Pole (2006-2008), Ann. Glaciol., 50, 35-41, https://doi.org/10.3189/172756409789097496, 2009.

Werder, M. A., Hewitt, I. J., Schoof, C. G., and Flowers, G. E.: Modeling channelized and distributed subglacial drainage in two dimensions, J. Geophys. Res.-Earth Surf., 118, 2140-2158, https://doi.org/10.1002/jgrf.20146, 2013.

Wessel, P. and Smith, W. H. F.: Free software helps map and display data, Eos, Trans. Am. Geophys. Union, 72, 441-446, https://doi.org/10.1029/90EO00319, 1991.

Wessel, P. and Smith, W. H. F.: New, Improved Version of Generic Mapping Tools Released, Eos, Trans. Am. Geophys. Union, 79, 579 p., 1998.

Wingham, D. J., Siegert, M. J., Shepherd, A. P., and Muir, A. S.: Rapid discharge connects Antarctic subglacial lakes, Nature, 440, 1033-1036, https://doi.org/10.1038/nature04660, 2006. 
Wright, A. P., Young, D. A., Roberts, J. L., Schroeder, D. M., Bamber, J. L., Dowdeswell, J. A., Young, N. W., Le Brocq, A. M., Warner, R. C., Payne, A. J., Blankenship, D. D.., van Ommen, T. D., and Siegert, M. J.: Evidence of a hydrological connection between the ice divide and ice sheet margin in the Aurora Subglacial Basin, East Antarctica, J. Geophys. Res.-Earth Surf., 117, F01033, https://doi.org/10.1029/2011JF002066, 2012.

Wright, A. P., Young, D. A., Bamber, J. L., Dowdeswell, J. A., Payne, a. J., Blankenship, D. D., and Siegert, M. J.: Subglacial hydrological connectivity within the Byrd Glacier catchment, East Antarctica, J. Glaciol., 60, 345-352, https://doi.org/10.3189/2014JoG13J014, 2014.

Young, D. A., Kempf, S. D., Blankenship, D. D., Holt, J. W., and Morse, D. L.: New airborne laser altimetry over the Thwaites Glacier catchment, West Antarctica, Geochem. Geophys. Geosyst., 9, Q06006, https://doi.org/10.1029/2007GC001935, 2008.

Young, D. A., Wright, A. P., Roberts, J. L., Warner, R. C., Young, N. W., Greenbaum, J. S., Schroeder, D. M., Holt, J. W., Sugden, D. E., Blankenship, D. D., van Ommen, T. D., and Siegert, M. J.: A dynamic early East Antarctic Ice Sheet suggested by ice-covered fjord landscapes, Nature, 474, 72-75, https://doi.org/10.1038/nature10114, 2011.
Young, D. A., Lindzey, L. E., Blankenship, D. D., Greenbaum, J. S., de Gorordo, A. G., Kempf, S. D., Roberts, J. L., Warner, R. C., van Ommen, T., Siegert, M. J., and le Meur, E.: Land-ice elevation changes from photon counting swath altimetry: First applications over the Antarctic ice sheet, J. Glaciol., 61, 17-28, https://doi.org/10.3189/2015JoG14J048, 2015.

Young, D. A., Schroeder, D. M., Blankenship, D. D., Kempf, S. D., and Quartini, E.: The distribution of basal water between Antarctic subglacial lakes from radar sounding, Philos. Trans. Roy. Soc. London A, 374, 20140297, https://doi.org/10.1098/rsta.2014.0297, 2016.

Young, D. A., Roberts, J. L., Ritz, C., Frezzotti, M., Quartini, E., Cavitte, M. G. P., Tozer, C. R., Steinhage, D., Urbini, S., Corr, H. F. J., van Ommen, T., and Blankenship, D. D.: High-resolution boundary conditions of an old ice target near Dome C, Antarctica, The Cryosphere, 11, 1897-1911, https://doi.org/10.5194/tc11-1897-2017, 2017.

Zwally, H. J., Schutz, B., Abdalati, W., Abshire, J., Bentley, C. R., Brenner, A., Bufton, J., Dezio, J., Hancock, D., Harding, D., Herring, T., Minster, B., Quinn, K., Palmi, S., Spinhirne, J., and Thomas, R.: ICESat's laser measurements of polar ice, atmosphere, ocean, and land, J. Geodynam., 34, 405-445, https://doi.org/10.1016/S0264-3707(02)00042-X, 2002. 